\title{
CONTRATOS DE SUSTENTAÇÃO DE VALOR: UMA ESTRUTURA DE GOVERNANÇA PARA ATIVOS ESPECÍFICOS, ESTRATÉGICOS E DIFÍCEIS DE MENSURAR
}

\author{
(D) Eliana Cunico ${ }^{1}$ (D) José Paulo de Souza ${ }^{2}$ (D) Sandra Mara de Alencar Schiavi $^{3}$
}

${ }^{1}$ Professora doutora, Universidade Estadual do Oeste do Paraná (UNIOESTE) - Curso de Administração. Marechal Cândido Rondon, PR - Brasil. eliana.cunico@ unioeste.br ${ }^{2}$ Professor doutor. Universidade Estadual de Maringá (UEM) - Centro de Ciências Sociais Aplicadas: Departamento de Administração. Maringá, PR - Brasil. jpsouza@ uem.br

${ }^{3}$ Professora doutora, Universidade Estadual de Maringá (UEM), Centro de Ciências Sociais Aplicadas: Departamento de Administração. Maringá, PR - Brasil. smaschiavi@uem.br

\section{Resumo}

Objetivo: Compreender como uma estrutura de governança pode coordenar recursos estratégicos compartilhados a fim de gerar e sustentar vantagens competitivas por meio da redução dos custos de transação, proteção e distribuição de valor.

Metodologia: A aplicação empírica foi desenvolvida no SAG Piscícola do Oeste Paranaense, com abordagem qualitativa, exploratória-descritiva. A coleta de dados envolveu 51 entrevistas, além visitas aos estabelecimentos e pesquisa documental, cujos resultados foram submetidos a análise de conteúdo por meio do software MAXQDA®.

Originalidade: A interdependência entre os agentes no agronegócio define complexidade para a coordenação de recursos estratégicos compartilhados visando, além da eficiência, gerar e sustentar vantagens competitivas, dado a existência de objetivos conflitantes. Tal condição remete à necessidade de formas específicas de governança para coordenação dos negócios, neste estudo abordados teoricamente a partir da Economia dos Custos de Transação, da Economia dos Custos de Mensuração em complementaridade com a Resource Based-View.

Contribuições teóricas/metodológicas: Teoricamente os CSV se mostram capazes de incentivar a competitividade horizontal, por meio do direito legal atualmente inexistente no SAG. Metodologicamente destaca-se a abrangência e a triangulação de dados em um SAG de referência para o agronegócio brasileiro.

Principais resultados: Como principal resultado, propõe-se os 'Contratos de Sustentação de Valor (CSV)' como uma estrutura de governança eficiente, direcionado à organização vertical e à competitividade horizontal no segmento produtor, com base em incentivos que recompensem com rendas ricardianas e com vantagens estratégicas, amparadas na mensuração.

Palavras-chave: Vantagem competitiva sustentável. Estrutura de governança. Dimensões mensuráveis dos ativos. SAG da piscicultura

\section{CONTRACTS FOR VALUE SUSTAINABILITY: A \\ GOVERNANCE STRUCTURE FOR SPECIFIC, STRATEGIC AND DIFFICULT-TO-MEASURE ASSETS}

\section{Abstract}

Objective: To understand how a governance structure can coordinate shared strategic resources in order to generate and sustain competitive advantages by reducing transaction costs, protecting and distributing value. Methodology: The empirical application was developed at Fish Farming SAG, located in Western Parana, with a qualitative, exploratory-descriptive approach. Data collection involved 51 interviewees, in addition to visits on productive facilities and secondary data analysis.The interviews were submitted to content analysis using the MAXQDA® software.

Originality: The interdependence between agents in agribusiness defines complexity to coordinate shared strategic resources, in addition to efficiency, generate and sustain competitive advantages, given the existence of conflicting goals. This condition refers to the need for specific forms of governance for business coordination, in this study theoretically approached from Transaction Costs Economy, Measurement CostsTheory in complementarity with the Resource Based View.

Theoretical / methodological contributions: Theoretically, SCV are able to encourage horizontal competitiveness by meansof legal right that does not currently exist in SAG. Methodologically, thescopeand triangulation of data in a reference SAG for Brazilian agribusiness stands out.

\begin{abstract}
Main results: as a mainresult, 'Support Contract Value (SCV)' is proposed as an effective governance structure, considering vertical organization and horizontal competitiveness in thesegment producer, basedon incentives thatreward with Ricardian rents and with strategic advantages, supported by measurement.
\end{abstract}

Keywords: Sustainable competitive advantage. Governance structure. Measurable dimensions of assets. Fish farming SAG.

CONTRATOS DE SOSTENIBILIDAD DE VALOR: UNA ESTRUCTURA DE GOBERNABILIDAD PARA ACTIVOS ESPECÍFICOS, ESTRATÉGICOS Y DIFÍCILES DE MEDIR

\begin{abstract}
Resumen
Objetivo: Comprender cómo una estructura de gobierno puede coordinar recursos estratégicos compartidos para generar y sostener ventajas competitivas al reducir los costos de transacción, proteger y distribuir valor. Metodología: La aplicación empírica se desarrollóenel SAG Piscícola do Oeste Paranaense, conun enfoque cualitativo, exploratorio-descriptivo. La recogida de datos incluyó 51 entrevistas, además de visitas a establecimientos e investigación documental, cuyos resultados se sometieron a análisis de contenido mediante el software MAXQDA®.

Originalidad: La interdependencia entre agentes de la agroindústria presentamos la complejidad para la articulación de recursos estratégicos compartidos, buscando, además de laeficiencia, generar y sostener ventajas competitivas, dada la existencia de objetivos contrapuestos. Esta condición se refiere a la necesidad de formas específicas de gobernanza para lacoordinación empresarial, en este estúdio teóricamente abordado desde la Economía de Costos de Transacción, desde la Economía de Costos de Medición en complementariedad com la Visión Basada en Recursos. Contribuiciones teóricas / metodologícas: Teóricamente, los CSV son capaces de incentivar la competitividad horizontal, mediante El derecho legal que actualmente no existe en el SAG. Metodológicamente, se destaca el alcance y triangulación de datos en un SAG de referencia para la agroindústria brasileña

Principales resultados: Como resultado principal, los 'Value Support Contracts (CSV)' se plantean como una estructura de gobernanza eficiente, orientada a la organización vertical y competitividad horizontal enel segmento productivo, basada en incentivos que premian con ricardiano y com ventajas estratégicas, sustentado en la medición.
\end{abstract}

Palabras-clave: Ventaja competitiva sostenible. Estructura de gobernanza. Dimensiones de activos medibles. Piscicultura SAG.

Cite as / Como citar

American Psychological Association (APA)

Cunico, E., Souza, J. P., \& Schiavi, S. M. de A. (2020, Oct./Dec.). Contratos de sustentação de valor: uma estrutura de governança para ativos específicos, estratégicos e difíceis de mensurar. Iberoamerican Journal of Strategic Management (IJSM), 19(4), 11-40. https://doi.org/10.5585/riae.v19i4.17673. 


\section{Introdução}

Esforços vêm sendo empreendidos no sentido de discutir o desenvolvimento de estratégias de coordenação que permitam gerar e sustentar valor diante da competitividade vigente em torno dos sistemas de agronegócio (Van Duren, Martin, \& Westgren, 1991; Zylbersztajn, 2005; Zylbersztajn \& Neves, 2010; Gomes \& Kliemann Neto, 2015; Caleman, Zylbersztajn, Pereira, \& Oliveira, 2017). Assim como em outras atividades econômicas, a concorrência, as mudanças institucionais e o avanço da tecnologia são fatores responsáveis pelas transformações no agronegócio, em especial, na produção de alimentos (Reifschneider \& Lopes, 2015).

Em cadeias agroalimentares, o foco está na estrutura vertical e nos relacionamentos diádicos, uma vez que a complexidade das relações está vinculada ao desenvolvimento de fornecedores e a coordenação dos sistemas de produção. As estratégias adotadas se voltam às decisões técnicas e orçamentárias, decisões na escolha de parceiros de negócio e nas decisões quanto a 'capacidade comparativa'das transações (Farina \& Zylbersztajn, 2003).

Argyres e Zenger (2012) definem por 'capacidade comparativa' o termo que explica como uma empresa avalia sua capacidade de entregar um produto ou serviço com menor custo, qualidade superior ou características de contratação de terceiros. Nessa perspectiva, as relações bilaterais envolvem tanto a análise das capacidades internas, como os custos de transação presentes no mercado. Assim, sempre que a firma puder economizar, ela o fará, seja produzindo internamente (integração vertical), por alternativas contratuais (formas híbridas) ou no mercado (spot), com base no alinhamento eficiente dos atributos (especificidade, frequência e incerteza) à estrutura de governança a cada transação (Williamson, 1985).

Neste estudo, as dificuldades de coordenação das transações realizadas entre dois segmentos de um Sistema Agroindustrial (SAG) serão consideradas a partir das perspectivas teóricas que envolvem a Resource Based View (RBV), Economy Transaction Costs (ECT) e a Economy Measurement Costs (ECM). Do ponto de vista da ECT - tendo como unidade de análise a transação -foram consideradas as estruturas de governança (EG), como mecanismos que influenciam os padrões de eficiência desses segmentos (Williamson, 1975). Na ECM o foco está nas dimensões mensuráveis dos ativos, a fim de estabelecer mecanismos de mensuração e distribuição de valor (Barzel, 1982, 2002; Trienekens, 2011). Em relação a RBV pura, as exigências do modelo VRIO de Barney (1991) e as condições estratégicas de Peteraf (1993), são consideradas por Storopoli, Binder e Maccari (2013) como um modelo universal para realizar análises gerenciais.

A colaboração tem sido tema de distintas discussões sobre estratégia. Há estudos anteriores que debatem a eficiência das estratégias de colaboração no uso de recursos entre universidade e indústria (Franco \& Haase, 2015); pautam a relevância das informações e conhecimentos compartilhados entre parceiros para atingir objetivos comuns (Niesten \& Jolink, 2015); apontam que diante de ações de cooperação em contexto de sustentabilidade, as formas de governança colaborativas (híbridas) são necessárias para criar legitimidade de tecnologias sustentáveis, sendo capazes de melhorar desempenhos 
social, ambiental e de governança (Nieste, Jolink, Jabbour, Chappin, \& Lozano, 2017). Em especial, a discussão sobre a relevância da cooperação e a necessidade de coordenação para o planejamento estratégico de cadeias de suprimento (Pooe \& Mahlangu, 2017; Pooe \& Munyanyi, 2019; Neves, Kalaki, Rodrigues, \& Gray, 2019) também é um tema emergente.Entretanto, a elaboração deste artigo foi motivada por considerar a ausência de discussões anteriores sobre a organização da colaboração vertical associada (em nível de cadeia produtiva) à competição horizontal (nível de empresa), amparada por híbridos formais, o que caracteriza um gap teórico ainda não abordado. Assim, este estudo se diferencia dos anteriores, uma vez que propõe o racional para análise de transações entre agentes de uma cadeia produtiva, com foco na obtenção de Vantagem Competitiva Sustentável (VCS), frente aos seus concorrentes. No modelo proposto se argumenta que, em determinadas condições - a presença de ativos específicos e estratégicos com mensuração e geração de valor conjunta - há a necessidade de uma estrutura de governança híbrida específica, capaz de coordenar mecanismos de incentivo e controle de resultados, e articular de forma eficiente as ações dos agentes.

Williamson (1985) define os ativos específicos como resultado de recursos tangíveis ou intangíveis, não passíveis de comercialização via mercado sem que haja perda de valor, sempre que uma relação comercial determinada via hierarquia ou contratos híbridos, for interrompida. Barney (1991) define como estratégicos, ativos que sejam valiosos, heterogêneos, não imitáveis e não substituíveis (VRIO). Assim, espera-se que ao conhecer e gerenciar adequadamente tais recursos, esses se tornem capazes de sustentar uma Vantagem Competitiva (VC) no longo prazo, mesmo diante da complexidade dos arranjos produtivos.

A complexidade das transações em SAGs exige coordenação por meio de adequados mecanismos de governança. Compreende-se que, teoricamente, a utilização de pressupostos teóricos da RBV, ECT e ECM, em complementaridade, permite analisar como ocorrem as transações, como o valor é gerado, mensurado e distribuído e, como ganhos de eficiência podem ser obtidos a partir da coordenação. Sob o enfoque teórico da Nova Economia Institucional (NEI), o uso da ECT e da ECM junto da RBV, foi sugerido por Augusto e Souza (2015), Ghozzy, Soregaroli, Boccaletti, \& Sauvée (2016) e Watanabe, Wever, Sousa, $\&$ Koenig (2016), tendo em vista as lacunas observadas por Foss e Foss (2004) dadoque juntas essas teorias são mais plausíveis na tentativa de explicar a eficiência no alcance de VC e VCS.

Ao propor uma maior compreensão sobre VCS, a seguinte questão se torna relevante: Como uma estrutura de governança pode coordenar recursos estratégicos compartilhados a fim de gerar e sustentar vantagens competitivas por meio da redução dos custos de transação, proteção e distribuição de valor? Como forma de responder ao questionamento, o objetivo do estudo consiste em compreender como uma estrutura de governança pode coordenar recursos estratégicos compartilhados a fim de gerar e sustentar vantagens competitivas por meio da redução dos custos de transação, proteção e distribuição de valor.

Para tanto, indica-se um modelo de estrutura de governança híbrida, responsável por fortalecer as relações de interdependência nas transações entre os segmentos produtor e processador, a partir de estratégias de elevação da competitividade horizontal, denominado como 'Contratos de Sustentação de 
Valor' (CSV). O termo competitividade horizontal adotado neste estudo, se refere a possibilidade de que, a partir da cooperação entre segmentos de um SAG, seja possível que tanto produtores como processadores, possam atingir melhores resultados. O modelo proposto contribui para a discussão acadêmica, dado que parte da utilização de bases teóricas sólidas, como a proposta de Williamsom (1975), que de forma seminal define o racional para a escolha dos arranjos de governança. E, por meio de argumentos relativos à diversidade de arranjos produtivos cujas configurações das transações se amparam em realidades empíricas distintas, propõe uma nova perspectiva de governança híbrida.

A fim de exemplificar o uso desse modelo de gestão, optou-se pelo SAG da piscicultura, atividade agropecuária brasileira que, embora apresente expressivo crescimento no mercado interno e avanço nas exportações em 2020 (Peixe Br, 2020), ainda requer maior atenção quanto às dificuldades de coordenação. O estudo aborda a relação entre produtor e processador, uma vez que esse elo da cadeia tem suas transações em processo de mudança, dado que a comercialização via mercado é gradativamente substituída por parcerias informais e contratos de integração (Brol \& Molinari, 2017).

Após esta introdução, o referencial teórico (2) apresenta pressupostos centrais e os argumentos para complementaridade teórica entre ECT, ECM e RBV. Em seguida (3), a metodologia para a construção e aplicação do modelo são detalhados. A quarta seção apresenta uma breve caracterização do SAG e os resultados do trabalho. Por fim, a quinta seção encerra com as considerações finais e sugestões para novas pesquisas.

\section{Referencial teórico}

Esta seção está organizada em dois âmbitos. O primeiro discute conceitos a respeito dos pressupostos centrais e das unidades de análise das três abordagens teóricas do estudo. O segundo, apresenta um conjunto de estudos anteriores que também utilizou a complementaridade entre tais perspectivas como embasamento. Por fim, as proposições teóricas são resumidas no Quadro 1.

\subsection{Pressupostos centrais e unidades de análise: RBV, ECT e ECM}

Neste estudo, a compreensão sobre a geração de VCS parte da análise de recursos e condições estratégicos, propostos pela RBV pura.Essa abordagem teórica considera as exigências do modelo VRIO_(i) valiosos (value) (ii) raros para concorrentes atuais e potenciais (rarity) (iii) inimitáveis (imitability) (iv) insubstituíveis (organizations- costly-to-imitate)propostas por Barney (1991), além das condições adicionadas por Peteraf (1993) (heterogeneidade, mobilidade imperfeita dos recursos, barreiras ex-ante e barreiras ex-post). A RBV pura defende ser possível maximizar resultados a partir de um conjunto de informações completas - situação em que empresas obtêm desempenho superior aos concorrentes, por possuírem recursos e capacidades diferenciados - gerando renda suficiente em equilíbrio (Barney, 1991). 
Lacerda, Teixeira, Antunes, \& Secundino (2014) destacam que o modelo VRIO é útil para analisar VCS, dado que o valor explica a combinação de recursos da empresa frente ao ambiente externo e como ela é capaz de explorar oportunidades ou neutralizar ameaças. Ademais, uma VC pode ser compreendida como um diferencial favorável à uma empresa em relação aos demais competidores. Tais vantagens, representam, de acordo com Peteraf (1993), ganhos de eficiência, alcançados pela habilidade de competir com custos menores e assim permitir rendas ricardianas, ou, por algum grau de exclusividade levar à lucros monopolistas.

Nesse sentido, observa-se que a discussão de como as empresas obtém desempenho superior ao de seus concorrentes é mantido com base na análise de seus recursos e rotinas, a fim de entender como ela exerce capacidade superior para manter e desenvolver tais recursos, tornando-se capaz de sustentar vantagens competitivas (Carvalho, Prevot, \& Machado, 2014). Ademais, “[...] ao contrário da análise proposta pelas cinco forças, a RBV lança um olhar mais microscópico para os agentes, tendo como unidade de análise os recursos da empresa" (Monteiro, 2017, p. 321). Entretanto, recursos e condições estratégicas individuais não são regra única.

Em transações nos SAGs não se pode considerar apenas o ambiente individual de uma empresa para tal análise, dado que muitas vezes os recursos e condições estratégicas se vislumbram por geração conjunta entre mais de um segmento. Neste estudo, serão nomeados 'recursos estratégicos compartilhados', aqueles cujo papel é determinante para estabelecer relações de interdependência, em função de investimentos específicos realizados pelas partes.Tais recursos são responsáveis por adicionar valor ao produto. Em outras palavras, a eficiência do mercado de fatores é fundamental para atingir desempenho esperado no mercado de produtos (Foss \& Foss, 2004; Augusto \& Souza, 2015; Dorobantu, Kaul, \& Zelner, 2017).

Wilden, Devinney, \& Dowling (2016) complementam que a pesquisa sobre estratégia moderna, tem buscado respostas para questões fundamentais, dentre elas: (i) por que e como as empresas se formam? (ii) como fazem para prosperar e sobreviver e (iii) como as empresas persistem e superam seus concorrentes? Com foco na terceira pergunta, que recai na explicação de VCS, este estudo considera que se faz necessário discutir também a transação, unidade de análise chave da ECT. A ECT discute a eficiência, decorrente do melhor alinhamento entre estrutura de governança e os atributos (especificidade, frequência e incerteza) permitindo atingir menores custos de transação (Williamson, 1985).

Os custos de transação são em suma determinados por três variáveis, dentre elas: (i) a incerteza, uma vez que não há como prever todos os aspectos que podem afetar a transação; (ii) a frequência, em que se verifica se as operações são isoladas ou recorrentes; (iii) a especificidade do ativo, uma vez que quanto maior ela for, maiores serão os custos para efetivar a transação, e maior será a dificuldade de realizá-las sem perda de valor (Williamson, 1985).

Para Williamson (1985), em função da transação se faz necessário avaliar qual estrutura de governança deve ser utilizada. Dentre as três possibilidades, é possível produzir internamente (integração 
vertical ou hierarquia), por alternativas contratuais (formas híbridas) ou no mercado spot (Williamson, 1985). O autor ainda conceitua que os custos de transação podem ser definidos como custos de negociar e redigir acordos (ex-ante) e garantir o cumprimento de um contrato (ex-post). Dessa forma, as condições de recorrência e reputação entre parceiros de negócio permite redução de custos de transação, dado que a continuidade dos negócios se torna mais importante do que ganhos momentâneos, denominados como comportamento oportunista (Ménard, 2018; Williamson, 1985).

Além disso, a presença de relações contínuas cria maior confiança, reduzindo custos de renegociação e hold-up contratual (Ménard, 2004, 2018) além de ser uma forma de coordenar as transações (Mozambani, Souza Filho \& Miranda, 2019) e minimizar riscos de investimento ex-ante (Foscaches \& Saes, 2017). As transações coordenadas também são consideradas mais eficientes uma vez que minimizam os chamados custos de mensuração em função dos atributos mensuráveis, unidade de análise da ECM. Dessa maneira, a ECM contempla as trocas e argumenta que um ativo possui vários tipos de atributos, sendo necessário proteger valor. Winkler e Souza (2013) explicam o arcabouço teórico da ECM pelas dimensões mensuráveis da transação e por seus pressupostos: direitos de propriedade e a informação.

O direito de propriedade é avaliado a fim de estabelecer mecanismos de mensuração e distribuição de valor críveis (Barzel, 2002). Dessa forma, a unidade de análise da ECM não deixa de ser a transação, porém é decomposta em dimensões ou atributos mensuráveis a fim de maximizar o lucro. As dimensões são mensuradas, a priori, em função do direito legal (legal property right) garantido pelo Estado, embora em alguns casos, o direito econômico (economic property right) possa ser responsável pela captura e distribuição de valor (Barzel, 2005, 2015).

Quanto à informação, Barzel (2002) a considera custosa e difícil de obter e, portanto, o agente que a detém possui vantagens nas negociações. Monteiro e Zylbersztajn (2011, p. 96) consideram que "[...] neste contexto, a presença de incerteza e assimetria faz com que incentivos econômicos sejam afetados pela estrutura de propriedade". Assim, sempre que a informação for admitida como primordial na geração e proteção de valor, direitos adicionais de controle são necessários (Barzel, 2002, 2015; Caleman et al., 2017). Embora outros conceitos sejam discutidos nas três teorias, dada a proposta de uso complementar, apresentase a seguir os argumentos a respeito dessa complementaridade.

\subsection{Indicações de complementaridade: RBV, ECT e ECM}

As estratégias de coordenação são amplamente discutidas na literatura (Lambert, 2008; Zylbersztajn \& Neves, 2010; Santos, Ferraz, Falqueto, \& Verga, 2017; Pooe \& Mahlangu, 2017; Pooe \& Munyanyi, 2019). Essas estratégias sugerem que VC são obtidas por meio do alinhamento da estrutura de governança aos atributos da transação de forma adequada (Williamson, 1985; Jacobides \& Winter, 2005; Crook, Combs, Ketchen, \& Aguinis, 2013; Esteves, Oliveira, \& Milanez, 2020) e consequentemente por sua capacidade de reduzir custos de transação e de mensuração (Ghozzy et al., 2016). Contudo, para explicar VCS a partir da eficiência, também se faz necessário conhecer os recursos e condições estratégicos, 
e como estes se organizam. Entretanto, conforme discutem Foss e Foss (2005) os custos de transação podem gerar perdas pela dissipação de valor nas relações entre os agentes, e a redução dessa dissipação cria valor, gerando resultados estratégicos.

Barney, Ketchen e Wright (2011), avançando na análise de Barney (1991), de que os atributos isolados pela cadeia de valor podem ser fonte de vantagens competitiva, explicam que a RBV foi integrada com outras correntes, como a Economia Organizacional, a Nova Economia Institucional e a Organização Industrial, o que possibilitou sua utilização em muitos campos de conhecimento como negócios internacionais, tecnologias, marketing e outras áreas. Neves, Hamachera e Cavarda (2014) e Santos et al. (2017) destacam a complementaridade entre RBV e ECT, uma vez que a ECT é baseada na redução dos custos, enquanto a RBV tem uma perspectiva a longo prazo e preocupa-se com a qualidade das transações. A essa ligação de complementaridade, Augusto e Souza (2015) propõe agregar também a ECM, para obter um enfoque conjunto capaz de explicar a relação entre VCS e as EG, associadas à mensuração de ativos específicos e estratégicos.

Ao racionalizar pressupostos de base das duas teorias, Argyres e Zenger (2012) ressaltam que mesmo distintas, ECT e RBV, argumentam a respeito da compreensão de como a firma é capaz de reduzir custos, maximizar sua eficiência e obter vantagens competitivas em relação aos concorrentes. Foss e Foss (2005, p. 551) afirmam: "Incorporating transaction costs more fullyinto the RBV introduces new sources of value dissipation and erosion". Nesse caso, conforme os autores, novas oportunidades estratégicas surgem pela redução dos custos de transação. Entretanto, o foco da unidade de análise proposto por cada uma delas, as distingue. Enquanto a ECT considera cada transação em particular, a RBV não apresenta consenso, pautando tanto os recursos como as condições dos recursos. Na ECM, a unidade de análise é consensualmente atribuída as dimensões mensuráveis do ativo.

A proposta de Augusto e Souza (2015) defende que a ECT parte da geração de incentivos ao alinhamento da estrutura de governança adequada para reduzir os custos de cada transação e pode ser complementada pela ECM que atua na criação, mensuração e na não dissipação do valor. Para os autores, ambas se complementam com a RBV, que tem por objetivo explicar como recursos e capacidades são capazes de produzir rendas ricardianas (eficiência) diante da presença de mecanismos que garantam os direitos de propriedade (proteção de valor). Santos et al. (2017) reforçam a complementaridade entre ECT e RBV, dado que esse diálogo é interpretado como riqueza aos estudos do campo.

Cardenas e Lopes (2006) consideram que a aliança dos pressupostos teóricos da ECT e da RBV possibilitam contribuições significativas à compreensão das causas que levam as empresas a cooperarem entre si. Ghozzy et al. (2016) afirmam que ambas, ECT e RBV podem ser utilizadas para explicar os limites da firma, dado que em 30 anos de debate, não houve uma explicação unificada quanto a reduzir custos de transação na RBV. Nesse sentido, RBV, ECT e ECM são teorias pautadas na eficiência, e juntas podem ser consideradas para discussões a respeito de maximização e proteção de valor de retornos acima da média. 
Os estudos em complementaridade são essenciais, dado que a base para a estratégia está nos pressupostos econômicos (Foss \& Knudsen, 2003; Aragão, Forte, \& Oliveira, 2010; Augusto \& Souza, 2015). Os autores Kretzer e Menezes (2006) também confirmam que a base da RBV está na economia organizacional, ratificando essa relação. A associação entre ECT e ECM nas discussões que envolvem vantagem competitiva é vinculada a relação que o ambiente exerce, seja nas restrições que impõe ou nas oportunidades que promove (Saes, 2009).

Para tanto, argumenta-se que a RBV deve ser associada aos pressupostos econômicos, uma vez que a transação é o momento em que se torna possível gerar e sustentar valor e, então, as firmas podem atingir rendas ricardianas, sendo mais eficientes do que os concorrentes. Este estudo concorda com a premissa de que a sustentação de $\mathrm{VC}$ ocorre de forma mais eficiente no interior das firmas, mas diante da presença de ativos específicos e estratégicos que não podem ser integrados, a hierarquia não resolve. Essa condição é um limite, uma vez que a RBV não discute a posse compartilhada de recursos, o que reforça a proposição de complementaridade.

Neste estudo, o uso conjunto das três abordagens visa trazer contribuição à discussão sobre coordenação para VCS. Em relação à coordenação, partindo de uma estrutura de governança que torne possível explorar e proteger recursos estratégicos em transações com recursos estratégicos compartilhados, a fim de atingir VCS, há congruência. Na visão da ECT a especificidade do ativo elevada indica hierarquia (Williamson, 1991). Na RBV o mesmo argumento é adotado, uma vez que condições de proteção a recursos estratégicos ocorrem no interior das firmas (Barney, 1991; Peteraf, 1993).

No entanto, em muitos setores da economia, principalmente nos que possuem alta rivalidade concorrencial, essa indicação pode ser inapropriada. Ao analisar a realidade dos SAGs, em especial nas relações caracterizadas por dependência bilateral, a hierarquia nem sempre é possível. Nessas relações de interdependência, recursos estratégicos são conjuntamente construídos e necessitam de coordenação. A forma com que essa coordenação é realizada, aponta Zylbersztajn (2005), influenciada pelo ambiente institucional, é que determina o SAG como mais ou menos eficiente. Ademais, Gomes e Kliemann Neto (2015), Pooe e Mahlangu (2017), Pooe e Munyanyi (2019) e Neves et al. (2019), indicam uma crescente de métodos colaborativos para estratégias em cadeias de suprimento. Hayashi, Nobuiuki, Prado-Gimenez, \& Pongeluppe (2018), sugerem que as pesquisas sobre estratégia devem atentar-se ao contexto empírico e, sobretudo, que apesar das dificuldades da operacionalização, a RBV é uma abordagem muito empregada na investigação empírica da estratégia.

Para tanto, os Contratos de Sustentação de Valor (CSV) são propostos no sentido de não apenas garantir o direito de propriedade das partes, mas de incentivar melhor desempenho conjunto. A finalidade é que ganhos de eficiência sejam obtidos a partir de estímulos à eficiência individual no segmento produtor: pelo uso de mecanismos de mensuração capazes de ampliar o controle sob atributos intrínsecos e como proteção de valor, a partir de relações de interdependência entre produtores e processadores diante de 
Cunico, E., Souza, J. P., \& Schiavi, S. M. de A. (2020, Oct./Dec.). Contratos de sustentação de valor: uma estrutura de governança para ativos específicos, estratégicos e difíceis de mensurar

recursos estratégicos capazes de gerar VCS. Não apenas a geração, mas a distribuição do valor importa (Foss \& Foss, 2004).

A questão da distribuição do todo entre as partes, a cada transação, é desconsiderada pela RBV dado que a geração de valor é observada no interior da empresa e, devido a isso, seus lucros já estariam alocados. Diante da análise de distribuição de lucros ao longo de agentes interligados em uma cadeia produtiva, os princípios da abordagem econômica dos direitos de propriedade propostos na ECM (Barzel, 2002, 2015) se tornam primordiais. Foss e Foss (2004) argumentam pela explicação de gerar e distribuir valor, aos segmentos a jusante. Portanto, elencam-se argumentos adotados por este estudo a partir de um raciocínio indutivo, que elabora proposições e sub proposições em complementaridade, no Quadro 1.

Quadro 1 - Proposições e sub proposições do estudo

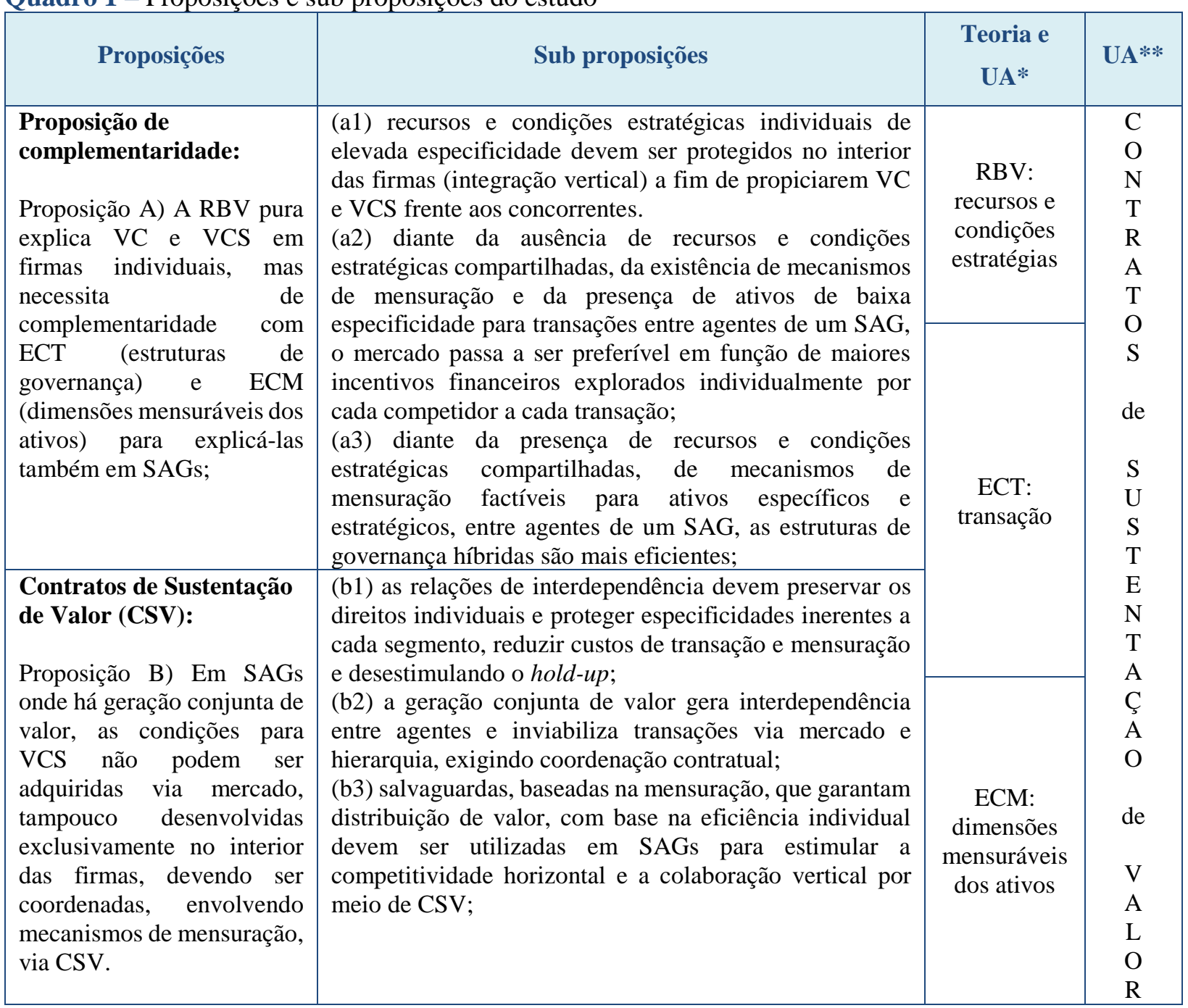

Nota: *UA- unidade de análise das teorias individuais e ** unidade de análise para complementaridade.

Fonte: Os autores.

Assim, os atributos de cada transação (ECT), as dimensões mensuráveis (ECM) e os recursos e condições estratégicas (RBV), são responsáveis por maximizar a geração e a proteção de valor sempre que, 
mesmo diante de ativos específicos e estratégicos, a integração vertical não puder ser aplicada, por conta de alguma interdependência entre segmentos do SAG. Os CSV são classificados como uma forma híbrida, como sugere Williamson (1991), mas apoiam-se na capacidade de coordenar relacionamentos, sem impor os limites da firma como barreira à cogeração de recursos estratégicos, aptos a VCS. Outros estudos recentes também abordaram discussões sobre coordenação das transações em SAGs, dado que essa é uma condição para geração e sustentação de VC a partir da análise das transações (Santos, Lourenzani, \& Lourenzani, 2019; Neves et al., 2019; Franco, Sudré, Bánkuti, \& Souza, 2018; Nogueira, Bánkuti, Lourenzani, Bánkuti, \& Lourenzani, 2018).

\section{Método}

Este estudo, de natureza qualitativa, caracteriza-se como exploratório e descritivo. Define-se como teórico-empírico, uma vez que associa a geração de conhecimentos à solução de problemas específicos (Gil, 2007). O uso de práticas interpretativas, descritivas e um conjunto de dados empíricos, conforme propõe Denzin e Lincoln (2005), tiveram como foco evidenciar recursos compartilhados, atributos de mensuração e a governança nas transações.

A coleta de dados foi realizada por meio de pesquisa documental (manuais, leis, regulamentos, contratos, websites, folders, projetos, dentre outros materiais institucionais) e por meio de entrevistas semiestruturadas. Para tanto, as entrevistas presenciais abordaram: (i) produtores - divididos em integrados e independentes (ii) processadores (agroindústrias cooperativas e agroindústrias privadas) e (iii) agentes chave (Emater e Prefeituras), a fim de promover contrapontos favoráveis à triangulação dos dados. Em todos os municípios o primeiro contato foi realizado com o agente-chave, por telefone, para agendamento prévio das visitas presenciais. Nessa fase, foram identificados 25 processadores ativos. Os agentes-chave foram fundamentais para condução da pesquisa, tanto no fornecimento de dados técnicos atualizados, bem como no acesso às agroindústrias e propriedades rurais.

O objeto de pesquisa selecionou a região pioneira e líder em produção de peixes em sistema de cultivo intensivo, o oeste do Paraná. A pesquisa abrangeu inicialmente 55 municípios. Como objeto de estudo, foram filtrados 18 municípios, os quais juntos representam $80 \%$ da produção do SAG em questão (Paraná, 2015) e abrigam as 25 plantas industriais de processamento. "No Brasil, uma das espécies que apresenta destaque econômico atualmente é a tilápia-do-Nilo (Oreochromis niloticus)" (Brito et al., 2014, p. 27), sendo a espécie líder de produção, responsável por 57\% da produção nacional de peixes de cultivo (Peixe Br, 2020).

Os instrumentos de coleta de dados foram aplicados com base em um recorte transversal, pois referem-se a um conjunto de dados oriundos de entrevistas em determinado período, ou seja, não se caracteriza como evolução de fenômenos ao longo do tempo (Malhotra, 2012). Os resultados não inferem caráter de generalização, uma vez que o interesse do problema é delimitado a um contexto específico sob a qual pretende-se conhecer uma realidade. Em observância a esse princípio, a coleta de dados teve uma 
duração de 3 meses (25/04/2018 a término em 25/07/2018) perfazendo um total de 51 entrevistados, divididos em (22) produtores (12) processadores e (17) agentes chave, conforme detalha o Quadro 2.

Quadro 2 - Informações sobre as entrevistas

\begin{tabular}{|c|c|c|c|c|c|c|}
\hline \multicolumn{7}{|c|}{ Municípios líderes em produção (Aprox. 70\% do total produzido no SAG) } \\
\hline Nova Aurora & Maripá & Toledo & $\begin{array}{c}\text { Assis } \\
\text { Chateaubrian } \\
d\end{array}$ & Palotina & $\begin{array}{c}\text { Nova Santa } \\
\text { Rosa }\end{array}$ & Cafelândia \\
\hline $\begin{array}{l}\text { Agente-chave } \\
\text { (41 min) }\end{array}$ & $\begin{array}{l}\text { Agente- } \\
\text { chave } \\
\text { (59 min) }\end{array}$ & $\begin{array}{l}\text { Agente- } \\
\text { chave } \\
(39 \mathrm{~min})\end{array}$ & $\begin{array}{l}\text { Agente- } \\
\text { chave } \\
(49 \text { min })\end{array}$ & $\begin{array}{c}\text { Não possuía } \\
\text { agente-chave } \\
\text { (aposentadoria }\end{array}$ & $\begin{array}{l}\text { Agente- } \\
\text { chave } \\
(37 \mathrm{~min})\end{array}$ & $\begin{array}{l}\text { Agente- } \\
\text { chave } \\
(41 \mathrm{~min})\end{array}$ \\
\hline $\begin{array}{c}\text { Produtor } \\
\text { Integrado (38 } \\
\text { min) }\end{array}$ & $\begin{array}{c}\text { Produtor } \\
\text { Integrado } \\
(30 \mathrm{~min})\end{array}$ & $\begin{array}{l}\text { Processador } \\
(36 \mathrm{~min})\end{array}$ & $\begin{array}{l}\text { Produtor livre } \\
\quad(18 \mathrm{~min})\end{array}$ & $\begin{array}{c}\text { Produtor Livre } \\
\text { (01H20min) }\end{array}$ & $\begin{array}{l}\text { Processador } \\
(27 \text { min })\end{array}$ & $\begin{array}{l}\text { Processador } \\
(50 \mathrm{~min})\end{array}$ \\
\hline $\begin{array}{l}\text { Produtor } \\
\text { integrado (28 } \\
\text { min) }\end{array}$ & $\begin{array}{l}\text { Produtor } \\
\text { livre } \\
\text { (33 min) }\end{array}$ & $\begin{array}{l}\text { Processador } \\
\text { (42 min) }\end{array}$ & $\begin{array}{c}\text { Produtor } \\
\text { integrado } \\
\text { (41min) }\end{array}$ & $\begin{array}{l}\text { Produtor } \\
\text { Integrado } \\
(45 \mathrm{~min})\end{array}$ & $\begin{array}{c}\text { Produtor } \\
\text { livre } \\
\text { (01H04min) }\end{array}$ & $\begin{array}{l}\text { Produtor } \\
\text { livre } \\
\text { (17 min) }\end{array}$ \\
\hline $\begin{array}{l}\text { Produtor } \\
\text { Livre } \\
(22 \mathrm{~min})\end{array}$ & & $\begin{array}{c}\text { Produtor } \\
\text { (Hierarquia) } \\
(52 \mathrm{~min})\end{array}$ & & $\begin{array}{l}\text { Processador } \\
(49 \mathrm{~min})\end{array}$ & & $\begin{array}{l}\text { Produtor } \\
\text { integrado } \\
(47 \mathrm{~min})\end{array}$ \\
\hline \multicolumn{7}{|c|}{ Municípios extras que também possuíam atividade de abate ativa em 2018} \\
\hline Corbélia & $\begin{array}{c}\text { Pato } \\
\text { Bragado }\end{array}$ & $\begin{array}{l}\text { Santa } \\
\text { Helena }\end{array}$ & $\begin{array}{l}\text { Marechal } \\
\text { Cândido } \\
\text { Rondon }\end{array}$ & $\begin{array}{c}\text { São Miguel do } \\
\text { Iguaçu }\end{array}$ & $\begin{array}{c}\text { Ouro Verde } \\
\text { do Oeste }\end{array}$ & Mercedes \\
\hline $\begin{array}{c}\text { Agente-chave } \\
\text { (35 min) }\end{array}$ & $\begin{array}{l}\text { Agente- } \\
\text { Chave } \\
\text { (32 min) }\end{array}$ & $\begin{array}{l}\text { Agente- } \\
\text { Chave } \\
\text { (42 min) }\end{array}$ & $\begin{array}{l}\text { Agente-Chave } \\
(01 \mathrm{H} 20 \mathrm{~min})\end{array}$ & $\begin{array}{l}\text { Agente-Chave } \\
\text { (52min) }\end{array}$ & $\begin{array}{l}\text { Agente- } \\
\text { chave } \\
\text { (33 min) }\end{array}$ & $\begin{array}{l}\text { Agente- } \\
\text { chave } \\
\text { (34min) }\end{array}$ \\
\hline $\begin{array}{l}\text { Processador } \\
\quad(57 \mathrm{~min})\end{array}$ & $\begin{array}{l}\text { Produtor } \\
\text { livre } \\
(42 \mathrm{~min})\end{array}$ & $\begin{array}{l}\text { Produtor } \\
\text { livre } \\
(23 \mathrm{~min})\end{array}$ & $\begin{array}{l}\text { Produtor } \\
\text { livre } \\
\text { (51 min) }\end{array}$ & $\begin{array}{l}\text { Produtor livre } \\
\quad(43 \mathrm{~min})\end{array}$ & $\begin{array}{c}\text { Produtor } \\
\text { livre } \\
\text { (33min) }\end{array}$ & $\begin{array}{l}\text { Produtor } \\
\text { livre } \\
(45 \mathrm{~min})\end{array}$ \\
\hline & & $\begin{array}{l}\text { Processador } \\
(53 \mathrm{~min})\end{array}$ & $\begin{array}{l}\text { Processador } \\
(01 \mathrm{H} 11 \mathrm{~min})\end{array}$ & $\begin{array}{l}\text { Processador } \\
(01 \mathrm{H} 18 \mathrm{~min})\end{array}$ & $\begin{array}{l}\text { Processador } \\
(33 \mathrm{~min})\end{array}$ & \\
\hline Cascavel & \multicolumn{2}{|c|}{ Santa Terezinha de Itaipu } & \multicolumn{2}{|c|}{ Serranópolis do Iguaçu } & \multicolumn{2}{|c|}{ Entre Rios do Oeste } \\
\hline $\begin{array}{l}\text { Agente-chave } \\
\text { (20 min) }\end{array}$ & \multicolumn{2}{|c|}{ Agente-chave (25 min) } & \multicolumn{2}{|c|}{ Agente-chave (31 min) } & \multicolumn{2}{|c|}{ Agente-chave (52 min) } \\
\hline $\begin{array}{l}\text { Processador } \\
(55 \mathrm{~min})\end{array}$ & & & \multirow{2}{*}{\multicolumn{2}{|c|}{ Produtor livre (22 min) }} & \multicolumn{2}{|c|}{ Processador (26 min) } \\
\hline $\begin{array}{l}\text { Produtor livre } \\
(40 \mathrm{~min})\end{array}$ & & & & & Produtor livi & (01H07min) \\
\hline
\end{tabular}

Fonte: Os autores.

A escolha dos entrevistados ocorreu com base no direcionamento dado por cada agente-chave, os quais indicaram produtores com maior tempo de atuação/experiência. Quanto as agroindústrias, 12 das 25 abordadas, aceitaram receber a pesquisadora no local para entrevistas gravadas. O roteiro das entrevistas foi organizado em blocos oriundos das categorias centrais descritas a seguir no Quadro 3, além dos blocos de caracterização dos respondentes e de perguntas direcionadas a validar a operacionalização dos Contratos de Sustentação de Valor (CSV). As devidas adaptações ao elaborar as perguntas, foram planejadas para respeitar a triangulação, diante da percepção dos produtores, processadores e agentes-chave. 
A fim de garantir transparência e confiabilidade à pesquisa, foram tomadas as seguintes medidas: (i) todas as entrevistas foram gravadas; (ii) todas as entrevistas foram transcritas na íntegra; (iii) as análises foram gerenciadas por meio do software MAXQDA®; (iv) a proposta dos CSV foi apresentada ao final de cada entrevista para validação dos participantes; (v) o arquivo final foi submetido a um software de identificação de plágio, a fim de melhorar aspectos de confiabilidade desta pesquisa. O recorte para a elaboração das categorias no Quadro 3, é derivado das unidades de análise e pressupostos teóricos centrais da RBV, ECT e ECM, obtidos na etapa de revisão da literatura. Após sua definição, as categorias foram utilizadas como base para a elaborar as entrevistas e para análise de conteúdo com base na proposta de Bardin (2010).

Quadro 3 - Categorias para análise de conteúdo.

\begin{tabular}{|c|c|c|}
\hline Teoria & Categorias & Principais Bases Teóricas \\
\hline \multirow{3}{*}{$\begin{array}{l}\text { Economia dos } \\
\text { Custos de } \\
\text { Transação (ECT) }\end{array}$} & Estrutur & \multirow{3}{*}{$\begin{array}{l}\text { North (1990); Williamson (1975, 1985, 1991); Jacobides e } \\
\text { Winter (2005); Zylbersztajn e Neves (2010); Crook et al. } \\
\text { (2013); Neves et al. (2014); Ghozzy et al. (2016); Foscaches e } \\
\text { Saes (2017); Dorobantu et al. (2017); Ménard (2018). }\end{array}$} \\
\hline & $\begin{array}{l}\text { Atributos da Transação } \\
\text { (Especificidade, } \\
\text { Frequência e Incerteza). }\end{array}$ & \\
\hline & Custos de & \\
\hline $\begin{array}{l}\text { Economia dos } \\
\text { Custos de } \\
\text { Mensuração - } \\
\text { ECM }\end{array}$ & $\begin{array}{l}\text { Dimensões Mensuráveis } \\
\text { dos Ativos }\end{array}$ & $\begin{array}{l}\text { Barzel (2002, 2005, 2015); Foss e Foss (2004); Trienekens } \\
\text { (2011); Monteiro e Zylbersztajn (2011); Winkler e Souza } \\
\text { (2013); Crook et al. (2013); Caleman et al. (2017); Monteiro } \\
\text { (2017); Ménard (2004). }\end{array}$ \\
\hline $\begin{array}{l}\text { Visão Baseada em } \\
\text { Recursos (VBR) }\end{array}$ & $\begin{array}{l}\text { Recursos Estratégicos e } \\
\text { Condições Estratégicas } \\
(\text { VRIO + CR) }\end{array}$ & $\begin{array}{l}\text { Barney (1991); Barney et al. (2011); Peteraf (1993); Foss e Foss } \\
\text { (2004); Aragão, et al. (2010); Storopoli et al. (2013); Carvalho } \\
\text { et at. (2014); Neves et al. (2014); Augusto e Souza (2015); } \\
\text { Ghozzy et al. (2016); Santos et al. (2017); Pooe e Mahlangu } \\
\text { (2017); Pooe e Munyanyi (2019). }\end{array}$ \\
\hline
\end{tabular}

Fonte: Os autores.

\section{Resultados}

\subsection{Resultados dos atributos das transações (etc.)}

De acordo com último anuário da piscicultura da Peixe $\mathrm{Br}$ (2020), a produção brasileira cresceu 4,5\% e atingiu 722.560 toneladas e, a partir de dados disponibilizados pela Intrafisch, o Brasil é o $4^{\circ}$ maior produtor de tilápia, perdendo apenas para Egito, Indonésia e China. No Brasil, o Paraná é o estado líder de produção de peixes de cultivo, e, em 2018, teve um crescimento de $16 \%$ em relação ao ano anterior e, a região oeste do Paraná, é líder em produção e processamento (Peixe Br, 2020).

Além das agroindústrias processadores, de acordo com a Peixe $\mathrm{Br}$ (2020) são considerados essenciais para a coordenação e o funcionamento do SAG piscícola, outros agentes, dentre eles: os fornecedores (ração, insumos, medicamentos e equipamentos), os produtores (alevinos, matrizes juvenis e engorda), os processadores (frigoríficos privados e cooperativas), diversas associações, consultores e técnicos. Além destes, há presença dos distribuidores, varejo e o consumidor final. A coleta de dados identificou 25 processadores ativos. $\mathrm{O}$ foco neste trabalho foi direcionado para as relações entre produtores 
e processadores, obtendo, além de suas próprias perspectivas, também uma terceira visão a partir de agentes chave de instituições de fomento dos municípios. Foram evidenciadas as três EG propostas na ECT (Williamson, 1985): mercado, híbridos e uma única iniciativa de hierarquia.

Corroborando com Williamson (1985), este estudo evidenciou que a indisponibilidade de acessar determinadas EG, implica em maiores custos de transação aos produtores e, conforme Watanabe et al. (2016), por meio delas busca-se proteger o valor gerado de apropriação externa indevida. A iniciativa de integração vertical é única e, embora lucrativa, não demonstra em primeira análise capacidade de ser fomentada, sendo identificada como condição única, remetida às vantagens de path dependence (North, 1990), decorrente de trajetória familiar de longos anos. Assim, para o SAG piscícola foi possível confirmar a proposição: (a1) recursos e condições estratégicas individuais de elevada especificidade devem ser protegidos no interior das firmas (integração vertical) a fim de propiciarem VC e VCS frente aos concorrentes.

Confirmando Reifschneider e Lopes (2015) e Brol e Molinari (2017) o mercado é uma estrutura que vem sendo gradativamente abandonada tanto por produtores como por processadores, uma vez que ambos admitem a necessidade de coordenar aspectos envolvendo especificidades temporal, locacional e física, discutidos a seguir. Aos produtores que optam pelo mercado, observa-se normalmente baixo investimento e pouca recorrência, confirmando a proposição: (a2) diante da ausência de recursos e condições estratégicas compartilhadas, da existência de mecanismos de mensuração e da presença de ativos de baixa especificidade para transações entre agentes de um SAG, o mercado passa a ser preferível em função de maiores incentivos financeiros explorados individualmente por cada competidor a cada transação.

Por fim, as formas híbridas foram identificadas sob duas perspectivas: os contratos formais e as parcerias informais. Os contratos formais referem-se a contratos de integração, utilizados entre agroindústrias cooperativas e seus cooperados, elaborados e desenvolvidos a partir do pioneirismo adotado na cadeia do frango, coordenados por meio do direito legal. As parcerias informais adotam apenas o compromisso de palavra entre as partes, assegurado pela recorrência e por regras do direito econômico. Ademais, foi identificada uma forma híbrida aqui denominada como semi-integração. Trata-se de uma cooperativa de produtores, formada para industrializar e vender o peixe, com produtores livres para negociar insumos via mercado.

No entanto, embora haja o predomínio de contratos formais em outras cadeias produtivas na região, como frango e suínos, a maior parte das transações no SAG da piscicultura ocorrem por meio acordos informais. De acordo com Caleman et al. (2017), a presença de transações coordenadas de formas distintas em um SAG motiva esforços para compreender a coexistência de arranjos em um ambiente institucional, o que para Monteiro (2017) necessita de um olhar mais criterioso sob as estratégias das transações.

As transações formalizadas são regidas pela Lei Nacional 13.288 de 16 de maio de 2016, tida como 'Lei da Integração'. Observa-se que nos contratos formais de integração, a integradora é responsável pelo 
fornecimento de insumos (alevinos, semente, medicamentos, assistência técnica, despesca e transporte) e o produtor integrado (fiel depositário responsável pela criação dos animais). De forma geral, o contrato determina que tal relação não se configura como prestação de serviço ou vínculo empregatício. O objetivo está em configurá-la por uma conjugação de recursos e esforços e pela distribuição justa dos resultados. O cumprimento desse tipo de contrato, depende de dimensões mensuráveis dos atributos (Barzel, 2002) e de como as regras do ambiente formal são executadas (Zylbersztajn, 2005). Nesse ponto, confirma-se a proposição (a3) diante da presença de recursos e condições estratégicas compartilhadas, de mecanismos de mensuração factíveis para ativos específicos e estratégicos, entre agentes de um SAG, as estruturas de governança híbridas são mais eficientes. A Figura 1 evidencia as EG adotadas pelos produtores.

Figura 1 - Características das estruturas de governança para produtores do SAG

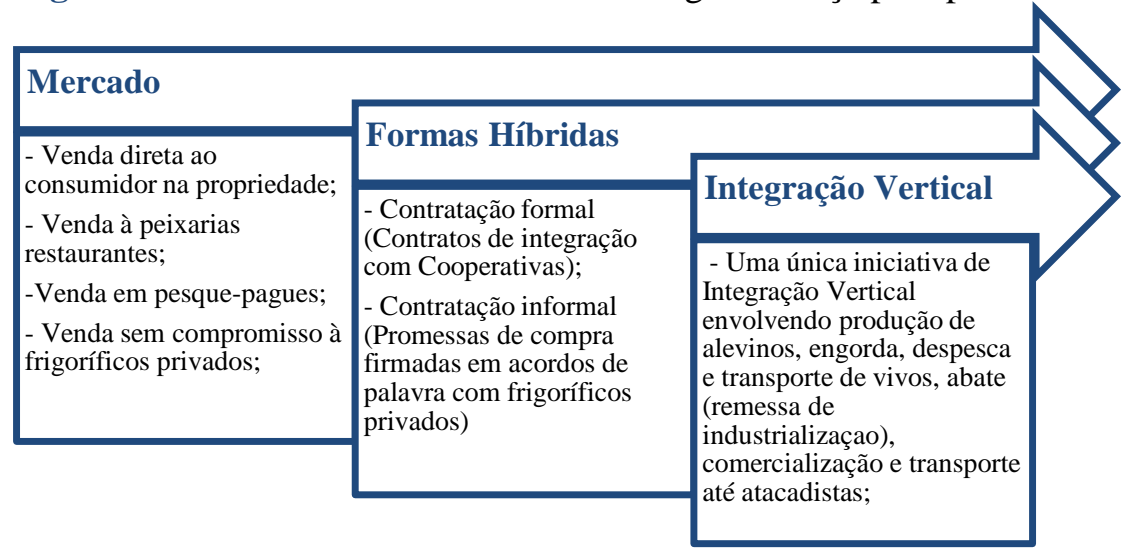

Fonte: Os autores.

Quanto aos processadores, de acordo com o Regulamento de Inspeção Industrial e Sanitária de Produtos de Origem Animal - RIISPOA (Decreto $n^{\circ} 30.691,1952$ ), dos quatro selos que podem ser obtidos, dois são emitidos pela esfera federal: Sistema de Inspeção Federal (SIF) e Sistema Brasileiro de Inspeção de Produtos de Origem Animal (SISB/POA). Em nível estadual a certificação permite comercialização no estado de origem e denomina-se como: Sistema de Inspeção do Paraná de Produtos de Origem Animal (SIP/POA). E o Sistema de Inspeção Municipal de Produtos de Origem Animal (SIM/POA), é chamado de 'inspeção municipal'. Para os entrevistados, o custo das certificações são elevados e burocráticos e dificultam acesso ao mercado.

Dentre os critérios de decisão para a compra de matéria-prima, destacam-se as relações de parceria, a qualidade do manejo e critérios de proximidade e facilidade de acesso ao campo, tendo a contínua análise de capacidade comparativa (Farina \& Zylbersztajn, 2003; Argyres \& Zenger, 2012; Augusto \& Souza, 2015). A mensuração de atributos justifica a coexistência de arranjos institucionais (Caleman et al., 2017), como na Figura 2. 
Cunico, E., Souza, J. P., \& Schiavi, S. M. de A. (2020, Oct./Dec.). Contratos de sustentação de valor: uma estrutura de governança para ativos específicos, estratégicos e difíceis de mensurar

Figura 2 - Características das estruturas de governança para processadores do SAG

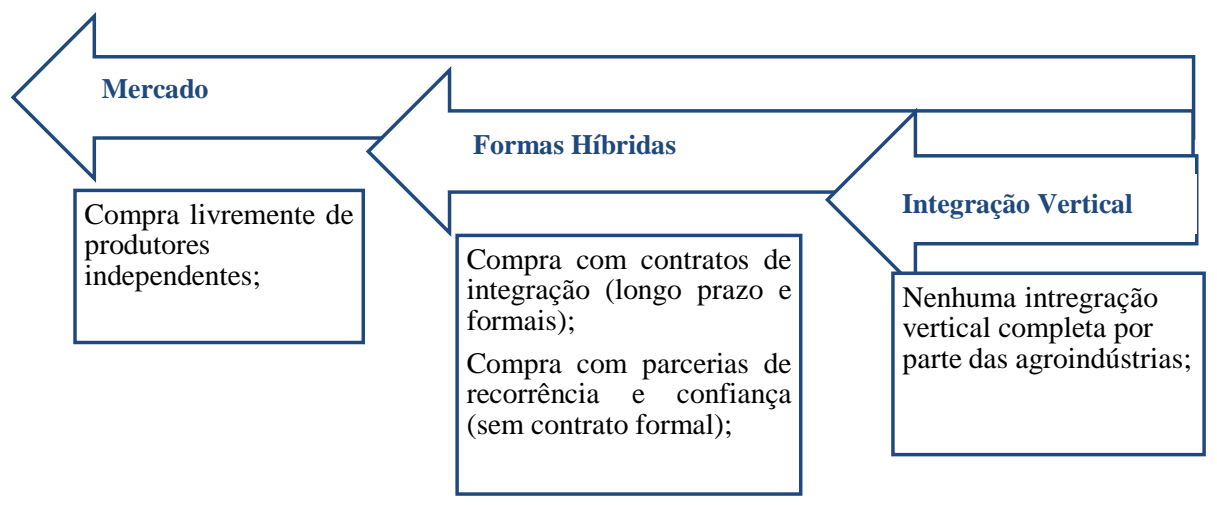

Fonte: Os autores.

Em todas essas condições, a cooperação entre agentes da cadeia produtiva, conforme propõe Cardenas e Lopes (2006), Franco e Haase (2015) e Niesten e Jolink (2015) é positiva para enfatizar estratégias. Quanto aos resultados adicionais da ECT, fundamentados em Williamson (1991), diante da presença de alta especificidade, maior controle deve ser imposto e, os híbridos e a hierarquia, são mais recomendados. O correto alinhamento proposto por Williamson (1985), também leva em conta os atributos de frequência e incerteza. Contudo, no SAG da piscicultura, variáveis como condições ambientais e de legislação impedem a hierarquia. O Quadro 4 resume as especificidades. Foram citados também aspectos sobre frequência (crise econômica e competição horizontal) e incerteza (clima e fluxos complexos que dificultam plano de abate).

Quadro 4 - Resumo das especificidades

\begin{tabular}{|c|c|c|}
\hline Especificidade de Marca & Especificidade Temporal & Especificidade de Ativos Dedicados \\
\hline $\begin{array}{l}\text { a) Marcas citadas como } \\
\text { reconhecidas: C-Vale e Copacol; } \\
\text { b) Volume de investimento } \\
\text { financeiro em marketing; } \\
\text { c) Força da imagem das } \\
\text { cooperativas locais; }\end{array}$ & $\begin{array}{l}\text { a) Sazonalidade de consumo no } \\
\text { e entressafra de alevinos no } \\
\text { inverno; } \\
\text { c) Decisão de quando e quanto } \\
\text { alojar é do produtor; } \\
\text { d) Manter peixe no tanque, após } \\
\text { estar em condição ideal para } \\
\text { abate; } \\
\text { e) prazo de validade do produto } \\
\text { acabado; } \\
\text { f) Tempo de Preparo da } \\
\text { despesca; }\end{array}$ & $\begin{array}{l}\text { a) Tecnologias de automação; } \\
\text { b) Equipamentos p/ aproveitar } \\
\text { subproduto; } \\
\text { c) Ociosidade da planta industrial; } \\
\text { d) Veículos - transporte do peixe vivo; } \\
\text { e) Gerador, aerador e instalação elétrica; } \\
\text { f) Tanques, remanescentes e estradas; } \\
\text { g) Tratadores automáticos; } \\
\text { h) Aparelhos - biometria e oxímetros; } \\
\text { i)Lagoas de decantação e acesso à } \\
\text { tanques; }\end{array}$ \\
\hline Especificidade Humana & Especificidade Física & Especificidade Locacional \\
\hline $\begin{array}{l}\text { a) Produtores engajados e atuantes; } \\
\text { b) Grau de profissionalização; } \\
\text { c) Conhecimento técnico; } \\
\text { d) Mão de obra treinada para tarefas } \\
\text { de risco: despesca e filetagem; } \\
\text { e) Especialistas em degustação; } \\
\text { f)Técnicos p/ construção de } \\
\text { tanques; }\end{array}$ & $\begin{array}{l}\text { a) Tilápias maiores; } \\
\text { b) O volume/tamanho do peixe } \\
\text { define o canal de venda; } \\
\text { c) Segregação e diferenciação } \\
\text { de destinos para cada padrão de } \\
\text { filé; } \\
\text { d) Produção de filé resfriado e } \\
\text { temperado; }\end{array}$ & $\begin{array}{l}\text { a) Prioridade nas transações } \\
\text { parceiros mais pró } \\
\text { agroindústrias } \\
\text { b) Limites de comercialização para } \\
\text { outras regiões; }\end{array}$ \\
\hline
\end{tabular}

Nota: Estas foram as condições de especificidade mais citadas, analisadas por frequência no MAXQDA®.

Fonte: Os autores. 
Foi possível constatar que nas relações entre agentes da piscicultura, os custos para efetivar as transações apresentam tanto de natureza ex ante (formalizar acordos) quanto ex post (garantir/ajustar acordos), confirmando as proposições teóricas da ECT de Williamson (1985). No Quadro 5 os mais relevantes são: estrutura de governança adotada não ser alinhada aos atributos da transação (a) e (f); os custos (c) e (g) se relacionam com dificuldades de estabelecer mecanismos de mensuração conjuntos; e os custos (d), (e), (h) e (i) classificam-se como custos de produção, embora alguns agravantes decorram da forma como o SAG é coordenado, como a falta de incentivos para procedimentos de depuração (pré-abate) entre os informais.

Quadro 5 - Custos de transação e outros custos assumidos nas transações

\begin{tabular}{|l|l|l|}
\hline \multicolumn{3}{|c|}{ Custos de transação aos produtores } \\
\hline \multicolumn{1}{|c|}{ Custos de Negociação e Renegociação } & \multicolumn{1}{c|}{ Monitoramento } & \multicolumn{1}{c|}{ Outros Custos de Produção } \\
\hline $\begin{array}{l}\text { a) Localizar e negociar com possíveis } \\
\text { compradores; } \\
\text { b) Renegociar prazos e substituir } \\
\text { cheques; }\end{array}$ & $\begin{array}{l}\text { c) Custos para avaliar causas de } \\
\text { mortalidade; }\end{array}$ & $\begin{array}{l}\text { d) Obtenção de licenças ambientais } \\
\text { e outorgas para uso da água; } \\
\text { e) Fretes de insumos e impostos; }\end{array}$ \\
\hline \multicolumn{3}{|c|}{ Custos de transação aos processadores } \\
\hline Custos de Negociação e renegociação & \multicolumn{1}{|c|}{ Monitoramento } & \multicolumn{1}{c|}{ Outros Custos de Produção } \\
\hline $\begin{array}{l}\text { f) Custos com funcionários que precisam } \\
\text { ir até a propriedade avaliar a matéria- } \\
\text { prima; }\end{array}$ & $\begin{array}{l}\text { g) Custos de técnicos para } \\
\text { controle e registro das } \\
\text { informações; }\end{array}$ & $\begin{array}{l}\text { h) Perdas decorrente da mortalidade } \\
\text { no transporte e depuração; } \\
\text { i) Frete, pedágio e impostos; }\end{array}$ \\
\hline
\end{tabular}

Nota: Estes foram os custos mais citados, analisados por frequência no MAXQDA®.

Fonte: Os autores, dados da pesquisa são de 2018.

\subsection{Resultados vinculados à mensuração (ECM)}

Quanto à mensuração, os principais custos evidenciados entre produtores e processadores referemse à necessidade de conferência conjunto de cada lote e o monitoramento por parte dos processadores quanto ao correto manejo de produção nas propriedades. Para que haja mensuração é necessário, de acordo com Barzel (2002), que seja definida a cesta de atributos associados ao ativo transacionado. Dentre os atributos considerados para a formação de preço pago pelo processador ao produtor no quilograma de tilápia, incorrem basicamente três, citados consensualmente por agroindústrias, produtores e agentes chave: o peso, a conversão alimentar e o tamanho de filé. O Quadro 6 expõe um conjunto de atributos que dificultam captura de valor. 
Quadro 6 - ECM: Dimensões Mensuráveis dos Ativos

\begin{tabular}{|l|l|l|}
\hline \multicolumn{2}{|c|}{ Intrínsecos } & \multicolumn{1}{c|}{ Extrínsecos } \\
\hline - Tamanho do filé & - Qualidade de ambiência & - Peso \\
\hline $\begin{array}{l}\text { - Conversão alimentar para } \\
\text { rendimento de filé }\end{array}$ & - Consistência carne & $\begin{array}{l}\text { Padronização de } \\
\text { tamanho no lote }\end{array}$ \\
\hline - Sabor & - Jejum para depuração & \\
\hline - Aroma & - Volume alojado x volume despescado & \\
\hline - Substâncias irregulares na carne & - Atendimento à padrões sanitários & \\
\hline
\end{tabular}

Nota: Estes foram os atributos mais citados, analisados por frequência no MAXQDA®.

Fonte: Os autores.

Diante da ausência de aplicação de mecanismos de mensuração mais precisos, as discordâncias quanto ao preço ocorrem em função de condições conhecidas, mas nem sempre mensuradas, impedem a devida remuneração e causam hold-upex-post (Foscaches \& Saes 2017; Foss \& Foss, 2004). Tais condições podem ser exemplificadas pela qualidade da água que consequentemente influenciará: no sabor da carne; na qualidade do efluente que retorna ao ambiente; no rendimento de filé e teor de gordura da carne; na presença de substâncias químicas no peixe que se configuram como nocivas à saúde humana; e nos índices de mortalidade do lote. Assim, a interdependência de recursos estratégicos sendo coordenada por meio de contratos de palavra não cria obstáculos ao hold-up, o que desestimula o produtor a investir e qualificar a produção e, impede o processador de estabelecer padrões acordados para redução de custos ex-ante e expost a cada transação, confirmando a proposição: (b1) as relações de interdependência devem preservar os direitos individuais e proteger especificidades inerentes a cada segmento, reduzir custos de transação e mensuração e desestimulando o hold-up.

É possível constatar que embora os atributos, tanto extrínsecos como intrínsecos, sejam reconhecidos por ambos os segmentos, a mensuração ainda não padronizada acarreta falhas na proteção e distribuição de valor. Barzel (2002) afirma que as falhas na distribuição de valor, muito em função da falta de capacidade para mensurar desempenhos individuais, ocorre pela indefinição da cesta de atributos, ou, pela dificuldade em mensurá-los. Nesse sentido a coordenação contratual das salvaguardas permitiria acordos mais estáveis e promissores à ambos. O esforço obtido na colaboração vertical, permitiria agregar valor ao produto, confirmando a proposição: (b2) a geração conjunta de valor gera interdependência entre agentes e inviabiliza transações via mercado e hierarquia, exigindo coordenação contratual.

A dificuldade de implementar mecanismos de mensuração conjuntos é vislumbrada nesta pesquisa diante da baixa presença de tecnologia e do limitante fluxo de informações entre os segmentos. Essa condição faz com que mensuração fora do contexto da firma eleve os custos (Winkler \& Souza, 2013). A presença de confiança e integridade, uniformidade e reputação e o reconhecimento da marca poderiam minimizá-los (Barzel, 2002). Para tanto, as regras de mensuração precisam ser pré definidas (Trienekens, 
2011; Caleman et al., 2017), em contratos que estimulem ao produtor a geração de atributos valorizados pelo processador.

O estudo demonstrou que há nichos diferentes para a tilápia. Há mercado consumidor tanto para preço baixo e padronização, como para elevado nível de qualidade e diferenciação. Assim, os processadores devem pré-definir salvaguardas contratuais que permitam, adequada distribuição de valor, conforme proposição: (b3) salvaguardas, baseadas na mensuração, que garantam distribuição de valor, com base na eficiência individual devem ser utilizadas em SAGs para estimular a competitividade horizontal e a colaboração vertical por meio de CSV.

\subsection{Resultados para VC e VCS (RBV) e modelo CSV}

Na prática, há iniciativas que apontam para junção de esforços entre segmentos na escolha de insumos, em aplicar melhores práticas de manejo e na busca por um produto de melhor qualidade. Isso indica corresponsabilidade entre as partes, o que justifica a adoção de formas híbridas na maior parte das transações na piscicultura. Nota-se que algumas implicações resultam da ausência de controle sobre Recursos VRIO (Barney, 1991) e de Condições Estratégicas (Peteraf, 1993), do correto alinhamento entre a estrutura de governança adotada em função da transação (Williamson, 1985) e, por fim, dos mecanismos de mensuração praticados em função dos atributos (Barzel, 2002). Teoricamente, Barney (1991) esclarece que o conjunto de recursos valiosos e raros proporciona $\mathrm{VC}$, ao passo que, complementado por recursos inimitáveis e insubstituíveis, torna-se capaz de permitir VCS.O SAG analisado possui condições para atingir VCS, desde que haja coordenação. Os resultados estão no Quadro 7. 
Quadro 7 - Recursos e condições estratégicas compartilhados entre os segmentos

\begin{tabular}{|c|c|c|c|}
\hline \multicolumn{4}{|c|}{ Recursos VRIO - Barney (1991) } \\
\hline Valiosos & Raros & Inimitáveis & Insubstituíveis \\
\hline $\begin{array}{l}\text { a) Planejamento e execução } \\
\text { do manejo; } \\
\text { b) Assistência técnica } \\
\text { gratuita; } \\
\text { c) Melhoramento genético; } \\
\text { d) Acesso a rações de } \\
\text { qualidade; } \\
\text { e) Preparo adequado de } \\
\text { tanques pré despesca; } \\
\text { f) Tecnologias e equipamentos } \\
\text { para aproveitar sub produtos; }\end{array}$ & $\begin{array}{l}\text { a) Qualidade e volume da } \\
\text { água na propriedade; } \\
\text { b) Padrões de solo; } \\
\text { c) Tecnologia bombear } \\
\text { água; } \\
\text { d)Tanques próximos do } \\
\text { abate; } \\
\text { e) Rastreabilidade e controle } \\
\text { de informações; } \\
\text { f) Criação de juvenis em } \\
\text { ambiente controlado; }\end{array}$ & $\begin{array}{l}\text { a) Presença de universidades e } \\
\text { pesquisadores de referência na } \\
\text { região; } \\
\text { b) Mão de obra especializada; } \\
\text { c) Organização cooperativa } \\
\text { local; } \\
\text { d) Infraestrutura disponível } \\
\text { para o volume de produção; }\end{array}$ & $\begin{array}{l}\text { a) Água em } \\
\text { condições } \\
\text { ideais; } \\
\text { b) Modelo de } \\
\text { negócio } \\
\text { familiar; }\end{array}$ \\
\hline \multicolumn{4}{|c|}{ Condições para Rendas Ricardianas - Peteraf (1993) } \\
\hline Heterogeneidade & Inimitabilidade & Barreiras ex ante & $\begin{array}{c}\text { Barreiras ex } \\
\text { post }\end{array}$ \\
\hline $\begin{array}{l}\text { a) Uso de bactérias vivas para } \\
\text { decompor matéria orgânica; } \\
\text { b) Manejo sustentável; } \\
\text { c) Documentação exportação; } \\
\text { d) Possuir certificado SIF; } \\
\text { e) Criação de juvenis; } \\
\text { f) Horas máquinas para } \\
\text { tanques; } \\
\text { g) Subsídio alevino e aerador; } \\
\text { h) Doação de caminhão feira; }\end{array}$ & $\begin{array}{l}\text { a) Monitoramento do } \\
\text { manejo pelo proprietário; } \\
\text { b) Localização geográfica } \\
\text { da propriedade; } \\
\text { d) Domínio total na } \\
\text { produção de ração e } \\
\text { alevinos; } \\
\text { e) Tecnologia de Despesca; }\end{array}$ & $\begin{array}{l}\text { a) Comercialização do peixe; } \\
\text { b) Falta de técnicos; } \\
\text { c) Burocracia p/ obterRGP; } \\
\text { e) Custo maiorpara novos } \\
\text { entrantes; } \\
\text { f) Pioneirismo do SAG local; } \\
\text { g) Logística das cooperativas; } \\
\text { h) Delimitação de atuação das } \\
\text { cooperativas; }\end{array}$ & $\begin{array}{l}\text { a) Alianças } \\
\text { /parcerias entre } \\
\text { agroindústrias; } \\
\text { b) Experiência } \\
\text { dos produtores } \\
\text { para atingir } \\
\text { padronização de } \\
\text { filé; }\end{array}$ \\
\hline
\end{tabular}

Fonte: Os autores.

Nota: Alguns dos recursos identificados são únicos ao SAG Piscícola do Oeste do Paraná.

A Figura 3 sintetiza a proposta dos CSV. Na primeira opção, diante da ausência de recursos e condições estratégicas individuais, baixa interferência dos atributos de transação e facilidade na captura e mensuração de valor dos atributos transacionados, o mercado spot é suficiente. Por outro lado, as teorias indicam e o estudo empírico confirma que, diante de ativos específicos e estratégicos individuais, que podem ser preservados no interior das firmas, a integração vertical é mais eficiente. No entanto, diante de recursos e condições estratégicas que são produzidos em atividades conjuntas em mais de um segmento em um SAG, da presença dos atributos da transação (especificidades, frequência e incerteza) e da necessidade de mensuração complexa, uma forma híbrida diferenciada coordena recursos e controla hold-up.

Os CSV sugerem o incentivo à eficiência individual, preservando a competitividade horizontal, a fim de estimular resultados conjuntos do SAG e permitir, por meio do direito legal, a distribuição de valor entre as partes. Complementarmente, o conceito de VCS é definido pela condição de não replicação imediata, ou seja, é necessário organizar tais condições (Peteraf, 1993) para que o SAG possa manter as vantagens identificadas, frente à outras regiões do país que estão se estruturando. Assim, seria possível atingir retornos financeiros superiores (renda ricardiana) (Barney, 1991). 
Figura 3 - Proposta para escolha da estrutura de governança

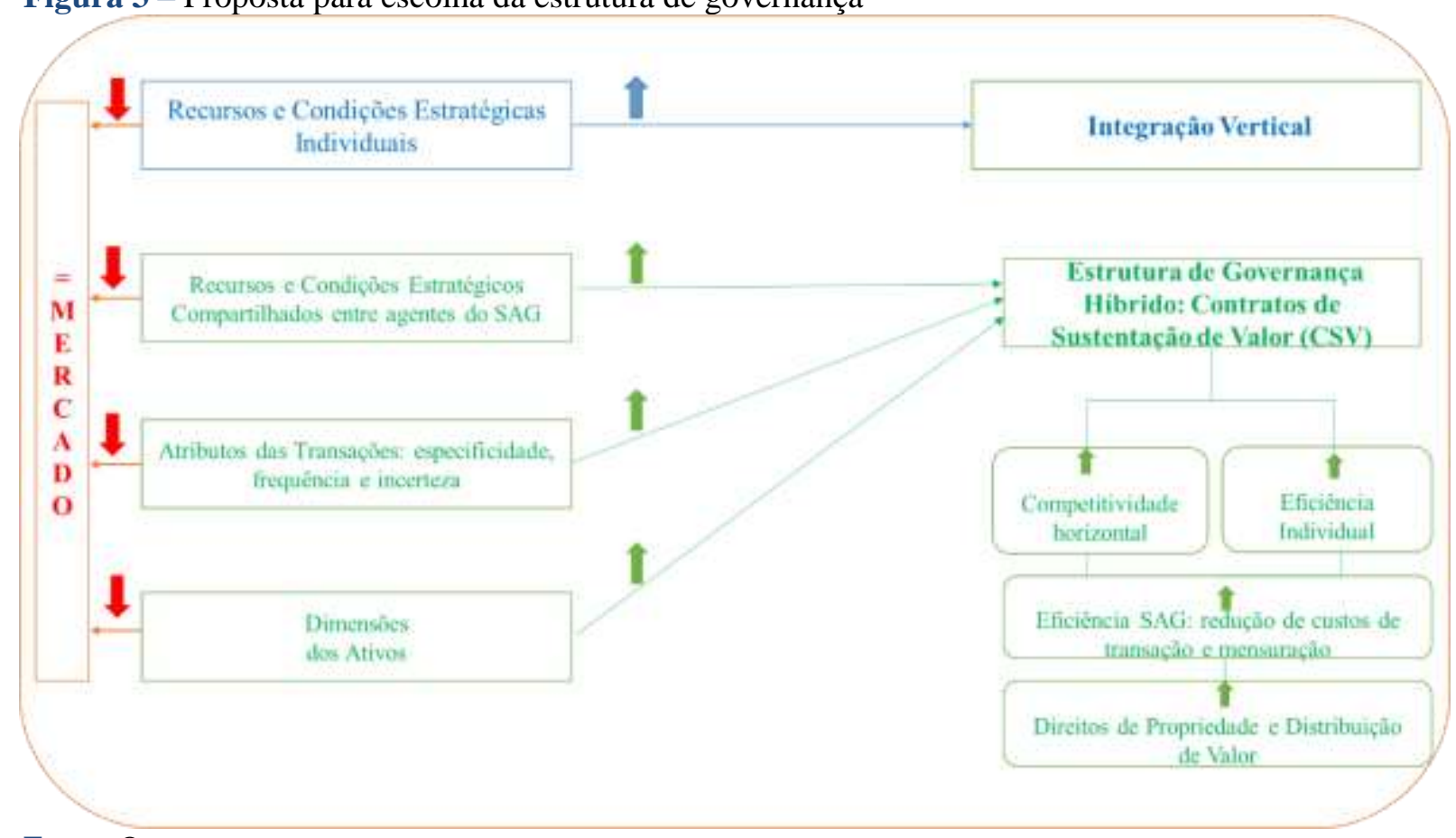

Fonte: Os autores.

De forma unânime, todos os entrevistados afirmam que ainda há falhas na distribuição de valor, muito em função da falta de capacidade para mensurar desempenhos individuais, pela indefinição da cesta de atributos (Barzel, 2002). Sobretudo, quando há coordenação, se torna possível promover transformações no resultado, como aponta o estudo de Saes (2009), que reflete sobre o fato de etapas à jusante da cadeia produtiva possuírem maior tendência a diferenciação, enquanto no segmento rural, produtos permanecem apenas como commodities. Os resultados deste estudo confirmam o que afirma Peteraf (1993), dado que as vantagens competitivas representam possibilidades e habilidades para competir com custos menores ou possuir algum grau de exclusividade.

Além disso, a ausência de direitos de propriedade bem definidos, decorrem da estrutura de governança adotada, situação constatada também por Winkler e Souza (2013). Portanto, ao identificar ativos específicos, estratégicos e difíceis de mensurar, com foi o caso do SAG da piscicultura as condições para VCS não podem ser adquiridas via mercado, tampouco desenvolvidas exclusivamente no interior das firmas, devendo ser coordenadas, envolvendo mecanismos de mensuração, via CSV. Essa constatação ratifica Santos et al. (2017) quanto à proposta de unir teorias para pesquisas que visem abordar estratégia.

Os CSV estabelecem como unidade de análise uma estrutura de governança específica, que coordene relações de interdependência, amplie a eficiência a partir de relações recorrentes e de longo prazo (ECT). Além disso, essas estruturas devem estimular a cogeração de recursos estratégicos capazes de sustentar vantagem competitiva (RBV), protegendo e distribuindo valor entre as partes (ECM) a partir de dimensões mensuráveis dos ativos. São formas híbridas com foco na contratação, a geração de incentivos 
de alta potência, uma vez que estímulos ao atendimento de requisitos do SAG, podem permitir o acesso a um mix de condições aptas a gerar retornos financeiros diferenciados.

Dentre os principais resultados, destaca-se que a eficiência por meio da redução de custos de transações, a mensuração conjunta e a cogeração de recursos estratégicos precisam ser coordenadas nas relações bilaterais presentes na piscicultura, o que ratifica a percepção dos incentivos de alta potência serem positivos ao SAG. A proposta foi apresentada ao final de cada uma das 51 entrevistas. Como resultado, se obteve a aprovação de 46 (90\%) dos 51 entrevistados, os demais apresentaram discordâncias parciais.

Dentre os critérios que necessitam maior coordenação, os entrevistados indicaram como principais pontos a serem alcançados com essa forma de contratação: (i) facilidade na obtenção de selos e outras formas de indicação de níveis de qualidade dos produtos; (ii) obtenção de rastreabilidade e denominação de origem, garantindo acesso à públicos/mercados específicos (ex: tipo exportação); (iii) obtenção de apoio e acesso facilitado a políticas públicas locais; (iv) apoio técnico junto às agências de fomento e universidades; (v) formação de grupos de desenvolvimento local; (vi) acesso exclusivo a propriedades modelos como forma de aprendizagem; (vii) definição e disseminação de critérios de prioridade nas transações de compra e venda; (viii) oferta de apoio técnico para ganhos de agilidade na obtenção de licenças (condições legais); (ix) possibilidade de direcionamento da matéria-prima a produtos específicos de maior valor (ex: filé fresco); (x) possibilidade da redução da burocracia junto aos órgãos fiscalizatórios; (xi) controle mais rígido do volume de peixes alojados e da qualidade da água efluente; (xii) viabilizar fiscalização mais intensiva das rações.

A percepção dos processadores teve similaridade quanto a necessidade de que a geração de incentivos e a distribuição de valor deve valorizar a eficiência individual, sendo base para a profissionalização. Para que isso ocorra, a contratação formal, de acordo com Ménard (2004), deve ser adotada como forma crível entre as partes. Houve convergência tanto por parte das agroindústrias, como dos produtores e agentes-chave de que os incentivos financeiros deveriam ser proporcionalmente distribuídos em função dos resultados alcançados, conforme indicação de Hayashi et al. (2018) sobre estudos de estratégia atentarem-se ao contexto empírico.

Com base no argumento de Saes (2009), a explicação para VC decorre do ambiente, seja pelas restrições impostas ou pelas oportunidades promovidas. A presente proposta determinou a necessidade de estabelecer benefícios e oportunidades admitidos como atrativos para realização de novos investimentos capazes de aprimorar o manejo e garantir a qualidade do ambiente de criação. Dentre as propostas destacamse duas: (i) facilidades em financiamento para novas tecnologias/ampliação da produção; (ii) a prioridade na venda e diferenciação do preço do $\mathrm{Kg}$ em função da categoria (nível de qualificação de cada propriedade).

Os estudos de Pooe e Mahlangu (2017) e de Pooe e Munyanyi (2019) foram confirmados, uma vez que as firmas poderiam compartilhar recursos para obter de diversas $\mathrm{VC}$, apoiadas na visão de cooperação dentro de um grupo estratégico. Este estudo confirmou essa possibilidade dado que a mensuração ocorre 
fora do contexto das firmas (Barzel, 1982) e, para tanto, esforços conjuntos devem ser tomados. O objetivo de minimizar custos a partir do controle de recursos estratégicos atende a crítica de Ghozzy et al. (2016), e os esforços de recorrência e confiança se mostram como mecanismos de coordenação (Mozambani, Souza Filho \& Miranda, 2019).

O estudo contribui significativamente com orientações teóricas aplicadas aos arranjos que se destacam pela divisão em estágios produtivos, como a produção de matéria-prima e seu processamento e distribuição. Ao tratar do uso de contratos que se orientam pela busca de eficiência, reforça os efeitos da cooperação para minimização de gargalos produtivos e estratégicos. Observou-se que com alguns investimentos e com ações que até reduziriam custos de transação entre as partes, seria possível avançar em termos da profissionalização da atividade e criar incentivos para fortalecer o SAG local. Não menos importante, o fato de acessar transações em um SAG que promova retornos e incentivos superiores, que seja um mecanismo de proteção contra hold-up e permita atingir novos mercados consumidores, se torne um dos objetivos almejados por produtores e processadores. Por fim, o Quadro 8 as categorias centrais, complementadas pelas evidências das entrevistas (quotations) que nortearam os resultados. Essa análise deve ser observada não como uma etapa final, mas como ponto de partida para a continuidade das pesquisas.

Quadro 8 - Associação entre lacunas e contribuições teóricas

\begin{tabular}{|c|c|c|}
\hline & & \\
\hline $\begin{array}{l}\text { Não há na literatura uma } \\
\text { discussão sobre uma estrutura } \\
\text { de governança específica para } \\
\text { ativos específicos, estratégicos } \\
\text { e difíceis de mensurar, obtidos } \\
\text { a partir da geração conjunta de } \\
\text { recursos entre mais de um } \\
\text { segmento em SAGs. }\end{array}$ & $\begin{array}{l}\text { Mercado: } \\
\text { E17: "Tem outros que nem isso fazem. E quando o } \\
\text { peixe chega na faixa de } 800 \text { a } 900 \text { gramas ele } \\
\text { executa a venda para esses frigoríficos, ele se } \\
\text { preocupa em vender". } \\
\text { E18L: "É tudo particular. Algumas vezes fizemos } \\
\text { financiamento, mas agora não queremos mais } \\
\text { fazer. E o peixe quando está pronto a gente liga }\end{array}$ & $\begin{array}{l}\text { Este artigo não discute } \\
\text { mercado ou integração } \\
\text { vertical (hierarquia). } \\
\text { Como contribuição } \\
\text { teórica propõe uma } \\
\text { forma r híbrida } \\
\text { direcionada para } \\
\text { arranjos que se } \\
\text { destacam pela divisão }\end{array}$ \\
\hline $\begin{array}{l}\text { Mercado: não se adapta para } \\
\text { coordenar especificidades } \\
\text { temporais de cadência de } \\
\text { produção e especificidades } \\
\text { locacionais envolvendo } \\
\text { recursos naturais; }\end{array}$ & & $\begin{array}{l}\text { como a produção de } \\
\text { matéria-prima e seu } \\
\text { processamento } \\
\text { distribuição. } \\
\text { caso, busca-se reduzir } \\
\text { custos de transações }\end{array}$ \\
\hline $\begin{array}{l}\text { Hierarquia: Em especial, no } \\
\text { agronegócio, são raras as } \\
\text { empresas que integram } \\
\text { verticalmente todas as etapas } \\
\text { de produção, haja visto a larga } \\
\text { escala produtiva e a } \\
\text { dependência de recursos não } \\
\text { suficientemente disponíveis } \\
\text { em um único local; }\end{array}$ & $\begin{array}{l}\text { parte arrendado para suprir o que eu precisc } \\
\text { produto. Eu pego o alevino de uma pessoa } \\
\text { produz há bastante tempo pra mim e compro m } \\
\text { ração direto na fábrica pois possuo } \\
\text { representação, sem atravessadores, busco } \\
\text { tenho os caminhões. Eu mesmo reformo }\end{array}$ & 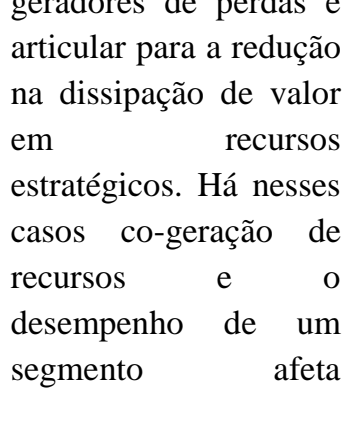 \\
\hline
\end{tabular}




\begin{tabular}{|c|c|c|}
\hline Categorias e Lacuna Teórica & Quotations & Contribuição teórica \\
\hline & $\begin{array}{l}\text { de } 40 \text { pessoas, de assistência técnica. Eu tenho a } \\
\text { comercialização do produto acabado, mas eu não } \\
\text { tenho mais frigorífico, eu terceirizo. Eu pego o } \\
\text { peixe na minha propriedade, levo até o frigorífico, } \\
\text { ele produz embala e me devolve. Fica produzido e } \\
\text { embalado por fulano para ciclano, emite uma nota } \\
\text { de remessa do peixe e depois posterior devolução } \\
\text { da mercadoria pronta, peixe eviscerado, ou filé ou } \\
\text { o produto que foi feito. E também vendo no gelo } \\
\text { produto para outros estados. Isso por causa do } \\
\text { volume de produto, eu opto por ter vários canais de } \\
\text { venda. Só vendo carga fechada, de volume de } \\
\text { carretas mesmo. Eventualmente tem distribuidores } \\
\text { que compram } 5 \text { a } 7 \text { toneladas, mas também eles } \\
\text { vêm buscar direto lá no frigorífico ou na } \\
\text { propriedade se for peixe no gelo. Eu tenho um } \\
\text { rótulo na empresa onde sou sócio também e vendo } \\
\text { um bom volume de peixes para eles". }\end{array}$ & $\begin{array}{l}\text { diretamente os ganhos } \\
\text { do outro. }\end{array}$ \\
\hline $\begin{array}{l}\text { Híbridos: A literatura discute } \\
\text { de maneira geral híbridos } \\
\text { formais ou informais, além de } \\
\text { condições de mensuração e } \\
\text { captura de valor específicas } \\
\text { para cadeias produtivas } \\
\text { específicas. }\end{array}$ & $\begin{array}{l}\text { E6: “A integração fornece todos os insumos e } \\
\text { garante que compra o peixe de mim". } \\
\text { E34: "Acho que o mais importante é manter a } \\
\text { fidelização com os parceiros. Tem muito produtor } \\
\text { que para ganhar } 0,30 \text { ou } 0,40 \text { centavos a mais ele } \\
\text { deixa um na mão e vende para outro. Eu tenho } \\
\text { fidelidade". } \\
\text { E34: "Olha se você tem para quem vender e que te } \\
\text { paga, é melhor ser livre. Mas se não tem essa } \\
\text { fidelidade, é melhor integração, você ganha } \\
\text { menos, mas tem mais segurança". } \\
\text { E39: "Não podemos fazer contrato e garantir } \\
\text { compra se não temos a venda garantida, a gente } \\
\text { anda conforme o nosso mercado". } \\
\text { E24: "Existe sim. Tem muita coisa que as vezes } \\
\text { você não consegue contemplar tudo isso dentro de } \\
\text { um contrato. Você pode fazer uma bíblia e ainda } \\
\text { vai ficar algo de fora. Então a gente entende que é } \\
\text { uma parceria e o peixe está lá sendo produzido sob } \\
\text { a responsabilidade do produtor, mas ele é da } \\
\text { cooperativa. Então é parceiro. Se um perder, outro } \\
\text { perde também". }\end{array}$ & \\
\hline $\begin{array}{l}\text { Atributos da Transação } \\
\text { (Especificidade, Frequência e } \\
\text { Incerteza): Os artigos discutem } \\
\text { teoricamente e empiricamente } \\
\text { as diferentes especificidades, o } \\
\text { papel da frequência e a } \\
\text { importância de prever } \\
\text { incertezas. No entanto, não } \\
\text { discutem como essas }\end{array}$ & $\begin{array}{l}\text { E48: "Hoje a gente não tem esse controle, porque } \\
\text { os produtores alojam por conta. E tem épocas do } \\
\text { ano que acumula o peixe e tem épocas do ano que } \\
\text { falta o peixe. A gente não tem condição de exigir } \\
\text { do produtor que ele fique dois ou três meses com o } \\
\text { tanque parado para a gente escalonar a produção". } \\
\text { E24: "Agora alguma coisa que a gente não } \\
\text { consegue controlar, um fator que nos incomoda } \\
\text { muito são as questões climáticas. Como é que você }\end{array}$ & $\begin{array}{l}\text { Este artigo demonstra } \\
\text { que em se tratando de } \\
\text { SAGs, a análise } \\
\text { empírica } \\
\text { especificidade, da } \\
\text { frequência e incerteza } \\
\text { precisa ser conduzida } \\
\text { de maneira a considerar } \\
\text { ambas as partes da }\end{array}$ \\
\hline
\end{tabular}




\begin{tabular}{|c|c|c|}
\hline Categorias e Lacuna Teórica & Quotations & Contribuição teórica \\
\hline $\begin{array}{l}\text { condições precisam ser } \\
\text { resolvidas em conjunto com os } \\
\text { parceiros quando se trata de } \\
\text { recursos conjuntos aplicados à } \\
\text { geração de valor. }\end{array}$ & $\begin{array}{l}\text { vai prever ou mensurar uma condição de uma } \\
\text { possível estiagem ou temperaturas extremas, seja } \\
\text { do frio ou do calor, isso gera um impacto muito } \\
\text { forte na produção. Até tecnologia tem, mas não a } \\
\text { um custo viável". }\end{array}$ & $\begin{array}{l}\text { transação, não apenas } \\
\text { como 'comprador e } \\
\text { vendedor'. Embora os } \\
\text { agentes assumam essas } \\
\text { posições, os resultados } \\
\text { dependem do } \\
\text { desempenho dos } \\
\text { parceiros de negócio. }\end{array}$ \\
\hline $\begin{array}{l}\text { Custos de Transação } \\
\text { O artigo manteve a } \\
\text { classificação dos custos de } \\
\text { transação propostas na } \\
\text { literatura para a análise. }\end{array}$ & $\begin{array}{l}\text { E43: "Sim, eu atendo eles aqui ou por telefone e é } \\
\text { feita a negociação de quantidade, um colaborador } \\
\text { vai até a propriedade para ver o peixe e de acordo } \\
\text { com a tabela, se chega no preço". }\end{array}$ & $\begin{array}{l}\text { Nenhuma nova } \\
\text { categoria de custos de } \\
\text { transação roi } \\
\text { identificada. Não houve } \\
\text { novas contribuições. }\end{array}$ \\
\hline $\begin{array}{l}\text { Dimensões Mensuráveis dos } \\
\text { Ativos } \\
\text { A literatura propõe a } \\
\text { discussão das dimensões } \\
\text { mensuráveis em atributos } \\
\text { intrínsecos e extrínsecos. }\end{array}$ & $\begin{array}{l}\text { E49: "não há consenso, peso e rendimento de filé, } \\
\text { mas não há um preço base, cada um faz seu preço". } \\
\text { E2: "Única coisa é a aparência, olhar no olho } \\
\text { mesmo e ver se o peixe tá bonito, está gordo. } \\
\text { Compram pelo tamanho, a parte de sabor não } \\
\text { valoriza não". }\end{array}$ & $\begin{array}{l}\text { Nenhuma nova } \\
\text { contribuição foi gerada, } \\
\text { apenas se identificou e } \\
\text { classificou os atributos } \\
\text { intrínsecos } \\
\text { extrínsecos em um } \\
\text { SAG. }\end{array}$ \\
\hline $\begin{array}{l}\text { Recursos Estratégicos e } \\
\text { Condições Estratégicas } \\
\text { (VRIO + CR) } \\
\text { A literatura argumenta que } \\
\text { ativos específicos } \\
\text { estratégicos devem ser } \\
\text { protegidos no interior das } \\
\text { firmas (hierarquia). Entretanto, } \\
\text { estudos anteriores não } \\
\text { discutem o fato de que em } \\
\text { SAGs, para se chegar a um } \\
\text { ativo específico e estratégico } \\
\text { há, muitas vezes, necessidade } \\
\text { de colaboração vertical entre } \\
\text { segmentos para atingir } \\
\text { determinados padrões de } \\
\text { produção e industrialização } \\
\text { não consolidados. }\end{array}$ & $\begin{array}{l}\text { E18: "E eu tenho que mandar um peixe de } \\
\text { qualidade. A vez passada ele pagou } \mathrm{R} \$ 4,50 \text { o Kg } \\
\text { do peixe dentro do tanque porque o peixe era de } \\
\text { qualidade. E essa vez ele disse o mesmo, eu tenho } \\
\text { que pegar o peixe de vocês para mandar para lá. E } \\
\text { ele disse, tá difícil achar peixe bom. Todo mundo } \\
\text { quer criar peixe, quer criar, mas o grande problema } \\
\text { é que não tratam o peixe do jeito que suponhamos } \\
\text { que dá um filé padrão. Eles querem filé padrão. } \\
\text { Para os outros ele tá pagando R } \$ 4,05 \text {, R } \$ 4,10 \text { ou } \\
\text { R\$ 4,20 e então ele falou pro meu filho, Douglas } \\
\text { você segura teu peixe, porque teu peixe eu não } \\
\text { posso perder. Segura mais uns dias [...] e ele veio } \\
\text { e negociou a R\$ 4,50 e nós seguramos para ele”. } \\
\text { E35: “(E35_IND) isso é fundamental, dado que: A } \\
\text { padronização do peixe é essencial para você } \\
\text { automatizar frigoríficos”. }\end{array}$ & $\begin{array}{l}\text { A contribuição teórica } \\
\text { está no fato deste artigo } \\
\text { argumentar que a } \\
\text { presença e a geração de } \\
\text { recursos estratégicos, } \\
\text { deve ser mapeada e } \\
\text { inserida por meio de } \\
\text { salvaguarda contratual } \\
\text { como forma de } \\
\text { incentivo e estímulo. } \\
\text { As ações devem ser } \\
\text { coordenadas por meio } \\
\text { de colaboração vertical } \\
\text { de forma a gerar } \\
\text { vantagem competitiva } \\
\text { na competição } \\
\text { horizontal, inserindo } \\
\text { ganhos de eficiência em } \\
\text { SAGs e redução da } \\
\text { dissipação de valor. }\end{array}$ \\
\hline
\end{tabular}

Fonte: Os autores, dados da pesquisa são de 2020. 


\section{Considerações finais}

Neste trabalho foram analisados os recursos e as condições estratégias, a estrutura de governança e os atributos mensuráveis das transações, com foco nos produtores e processadores da piscicultura no Oeste do Paraná. Nesse sentido, o presente trabalho atingiu o objetivo geral uma vez que foi possível compreender como uma estrutura de governança pode coordenar recursos estratégicos compartilhados a fim de gerar e sustentar vantagens competitivas por meio da redução dos custos de transação, proteção e distribuição de valor. Esses pontos chaves foram teoricamente embasados na RBV, em complementaridade com a ECT e a ECM.

Foi possível identificar a presença de especificidade de ativos, recursos estratégicos compartilhados entre segmentos, mecanismos de mensuração executáveis e, sobretudo, potencial para obtenção de VCS no SAG.Foi constatada que há interação entre as unidades de análise de cada uma das teorias utilizadas, quando se busca compreender a eficiência, a partir dos resultados empíricos analisados. Foram caracterizadas as estruturas de governança e um extenso conjunto de dimensões mensuráveis dos ativos transacionados.

Como principal contribuição teórica, uma estrutura de governança específica para modelos híbridos com a presença de ativos específicos, estratégicos e difíceis de mensurar foi proposta. Embora outros estudos já tenham comprovado a relevância da colaboração em cadeias de suprimento, este trabalho argumenta que a presença e a geração de recursos estratégicos devem ser mapeadas e inseridas por meio de salvaguarda contratual capaz de promover incentivos e estímulos, dito de outra forma, gerar valor e evitar a dissipação do valor gerado. As ações devem ser coordenadas em SAGs a partir do direito legal, com mecanismos formais de colaboração vertical e competição horizontal, primando ganhos de eficiência.

Considera-se que o conjunto das proposições '(a1), (a2), (a3)' foram confirmadas, dado que para explicar VC e VCS, não apenas a depender da estrutura de governança adotada, mas também das dimensões mensuráveis dos atributos do ativo e da análise de recursos estratégicos individuais e compartilhados foram necessárias. A sub proposição 'a1' retrata que a integração vertical não se adequa ao SAG. A sub proposição 'a2' que trata das transações via mercado, expôs que a ausência de formalização, sem qualquer estruturação de parcerias, está levando produtores e processadores a prejuízos. Quanto a proposição 'a3', confirmou-se que as relações contratuais se postam de maneira dominante no SAG e admitem condições de interdependência, mas com falhas de coordenação, dado a predominância de acordos informais.

As proposições '(b1), (b2) e (b3)' também se confirmaram, dado a necessidade de manter uma estrutura de contratação, uma vez que recursos VRIO e condições estratégicas são compartilhadas entre segmentos. A sub proposição ' $b 1$ ' foi constatada nas relações entre produtores e processadores, dado que ambos são responsáveis por compor atributos que permitem gerar e sustentar valor. A sub proposição 'b2' confirma haver perda de valor nas transações, se essas não mantiverem interdependência por meio de coordenação contratual. Por fim, a proposição 'b3' confirma os CSV como uma alternativa potencialmente viável, responsável por salvaguardas baseadas na mensuração, capazes de garantir que eficiência individual seja captada e, a colaboração entre segmentos, seja capaz de promover a eficiência do SAG. Assim, diante 
da contratação, da mensuração e de direitos de propriedade definidos, as salvaguardas baseadas no direito legal geram maior segurança aos agentes da transação, em detrimento de negociações amparadas no direito econômico.

Dentre as limitações reconhecidas, destaca-se que o conjunto de ações e resultados propostos pelos CSV podem ser ampliados à medida que a organização evolui. A racionalidade limitada também impõe restrições as ações cabíveis em um contrato no longo prazo. Não obstante, considera-se que o trabalho foi aplicado sob uma dimensão temporal transversal e estática, em um único SAG. Como sugestão para futuros estudos, recomenda-se que o objetivo de replicação possa inspirar pesquisadores em outros contextos, pela visão quantitativa e em outras perspectivas temporais. Além disso, sugere-se questões pontuais, como: a padronização de atributos mensuráveis e contratáveis, aliada a transmissão de informações críveis, permite reduzir custos de transação? Estratégias de estímulo a competitividade individual podem de ampliar a eficiência coletiva de outros SAGs?

\section{Agradecimentos}

Programa de Pós-Graduação em Administração - PPA/UEM.

\section{Referências}

Aragão, L. A., Forte, S. H. A. C., \& Oliveira, O. V. (2010). Visão baseada em recursos e capacidades dinâmicas no contexto brasileiro: a produção e a evolução acadêmica em dez anos de contribuições. REAd - Revista Eletrônica de Administração, 16(2), 373-396.

Argyres, N. S., \& Zenger, T. R. (2012). Capabilities, transaction costs, and firm boundaries: a dynamic perspective and integration. SSRN - Social Science Research Network, 23(6), 1643-1657. doi: $10.2307 / 23362018$

Augusto, C. A., \& Souza, J. P. (2015). Transaction costs economics and resource-based view: complementary aspects in the treatment of governance structures. REBRAE - Revista Brasileira de Estratégia, 8(2), 173-193. doi: 10.7213/rebrae.08.002.AO04

Bardin, L. (2010). Análise de conteúdo. São Paulo, SP: Edição 70.

Barney, J. B. (1991). Firm resources and sustained competitive advantage. Journal of Management, 17(1), 99-120.

Barney, J. B., Ketchen, D. J., \& Wright, M. (2011). The future of resource-basead theory: revitalization or decline? Journal of Management, 37(5), 1299-1315. doi: 10.1177/0149206310391805

Barzel, Y. (1982). Measurement cost and the organization of markets. Journal of Law and Economics, 25(1), p. 27-48.

Barzel, Y. (2005). Organizational forms and measurement costs. Journal of Institutional and Theoretical Economics, 161(3), 357-373.

Barzel, Y. (2002). A theory of the state. Cambridge, UK: Cambridge University Press. 
Barzel, Y. (2015). What are 'property rights', and why do they matter? A comment on Hodgson's article. Journal of Institutional Economics, 11(4), 719-723. Recuperado de: https://doi.org/10.1017/S1744137415000181.

Brito, J. M., Ferreira, A. H. C., Santana Júnior, H. A., Araripe, M. N. B. A., Lopes, J. B., Duarte, A. R., ... Silva A. L. (2014). Policultivo de tilápias-do-nilo (oreochromis niloticus) e camarão marinho (litopenaeus vannamei) em tanques-rede - revisão. Revista Eletrônica Nutritime, 11(2), 3225-3237.

Brol, J., \& Molinari, D. (2017). Piscicultura no Paraná: rumo as 100 mil toneladas. Aquaculture Brasil, 17, 45-49. Recuperado de: https:/www.aquaculturebrasil.com/artigo/48/piscicultura-no-parana$\%$ E2\%80\%93-rumo-as-100-mil-toneladas-.

Caleman, S. M. Q., Zylbersztajn, D., Pereira, M. W. G., \& Oliveira, G. M. (2017). Organizational tolerance in agro-industrial systems: an empirical application for the meat sector. Revista de Administração (São Paulo), 52(4), 456-466. doi:10.1016/j.rausp.2016.11.001

Cardenas, L. Q., \& Lopes, F. D. (2006). A formação de alianças estratégicas: uma análise teórica a partir da dependência de recursos e da teoria dos custos de transação. Cadernos EBAPE, 4(2), 1-8.

Carvalho, D. M., Prevot, F., \& Machado, J. A. D. O. (2014). O uso da teoria da visão baseada em recurso em propriedades rurais: uma revisão sistemática da literatura. Revista de Administração (São Paulo), 49(3), 506-518. doi: 10.5700/rausp1164

Crook, T. R., Combs, J. G., Ketchen, D. J., \& Aguinis, H. (2013). Organizing around Transaction Costs: What have we learned and where do we go from here? Academy of Management Perspectives, 27(1), 63-79. Recuperado de: https://doi.org/10.5465/amp.2012.0008.

Decreto $n^{\circ}$ 30.691, de 29 de março de 1952. (1952, 7 de julho). Aprova o Novo Regulamento da Inspeção Industrial e Sanitária de Produtos de Origem Animal. Diário Oficial da União.

Denzin, N., \& Lincoln, Y. (2005). Introduction: the discipline and practice of qualitative research. In N. Denzin \& Y. Lincoln (Eds.), The sage handbook of qualitative research (p. 699-714). Thousand Oaks, CA: Sage, 2005.

Dorobantu, S., Kaul, A., \& Zelner, B. (2017). Nonmarket strategy research through the lens of new institutional economics: an integrative review and future directions. Strategic Management Journal, 38(1), 114-140. Recuperado de: https://doi.org/10.1002/smj.2590

Esteves, M. C., Oliveira, A. R., \& Milanez, A. P. (2020). Exportações de produtos agrícolas e o ambiente portuário: a perspectiva da teoria dos custos de transação. Revista de Economia e Sociologia Rural, 58(1), 1-14. Recuperado de: https://doi.org/10.1590/1806-9479.2020.192957.

Farina, E. M. M. Q., \& Zylbersztajn, D. (2003). Economics of Networks and Patterns of Competition in Food Business. In Proceedings of $4^{\circ}$ International Conference on Agri-Food Chain Management. Recuperado de: http://www.fundacaofia.com.br/pensa/anexos/biblioteca/632007145029_.pdf.

Foscaches, C., \& Saes, M. S. M. (2017). Economia dos custos de transação e teoria da identidade: um estudo bibliométrico. Desafio Online, 5(3), 353-365.

Foss, K., \& Foss, N. J. (2004). The next step in the evolution of the vbr: integration with transaction cost economics. Management Revue, 15(1),107-121.

Foss, K., \& Foss, N. J. (2005). Resources and transaction costs: how property rights economics furthers 
the resource-based view. Strategic Management Journal, 26(6), 541-553.

Foss, N. J., \& Knudsen, T. (2003). The resource-based tangle: towards a sustainable explanation of competitive advantage. Managerial and Decision Economics, 24(4), 291-307.

Franco, M., \& Haase, H. (2015). University-industry cooperation: researchers'motivations and interaction channels. Journal of Engineering and Technology Management, 36, 41-51. Recuperado de: https://doi.org/10.1016/j.jengtecman.2015.05.002

Franco, J. O. B., Sudré, C. A. G. W., Bánkuti, S. M. S., \& Souza, J. P. (2018). A coordenação entre produtores e processadores piscícola no norte do Paraná. Economia \& Região, 6(2), 27-45. doi: $10.5433 / 2317-627 X .2018 v 6 n 2 p 27$

Gil, A. C. (2007). Como elaborar projetos de pesquisa (4a ed.). São Paulo, SP: Atlas.

Ghozzy, H., Soregaroli, C., Boccaletti, S., \& Sauvée, L. (2016). Impacts of non-GMO standards on poultry supply chain governance: transaction cost approach vs resource-based view. Supply Chain Management: an International Journal, 21(6), 743-758.

Gomes, L. C., \& Klieman Neto, F. J. (2015). Métodos colaborativos na gestão de cadeias de suprimentos: desafios de implementação. RAE - Revista de Administração de Empresas, 55 (5), 563-577. Recuperado de: https://doi.org/10.1590/S0034-759020150508

Hayashi, P., Nobuiuki, I., Prado-Gimenez, F. A., \& Pongeluppe, L. (2018). Entendimentos e desentendimentos da pesquisa empírica da visão baseada em recursos: uma abordagem exploratória. Estudios Gerenciales, 34(149), 469-480. doi: http://dx.doi.org/10.18046/j.estger.2018.149.2828.

Jacobides, M. G., \& Winter, S. G. (2005). The co-evolution of capabilities and transaction costs: explaining the institutional structure of production. Strategic Management Journal, 26(5), 395-413. Recuperado de: https://repository.upenn.edu/cgi/viewcontent.cgi?article=1137\&context=mgmt_papers.

Kretzer, J., \& Menezes, E. A. (2006). A importância da visão baseada em recursos na explicação da vantagem competitiva. Revista de Economia Mackenzie, 4(4), 63-68.

Lacerda, D. P., Teixeira, R., Antunes, J., \& Secundino, L. H. C. N. (2014). Estratégia baseada em recursos: 15 artigos clássicos para sustentar vantagens competitivas. Porto Alegre, RS: Bookman.

Lambert, D. M. (2008). Supply chain management: process, partnerships, performance (3a ed.). Sarasota, FL: SCMI - Institute Supply Chain Management.

Lei $n^{\circ} 13.288$, de 16 de maio de 2016. (2016, 17 de maio). Dispõe sobre os contratos de integração, obrigações e responsabilidades nas relações contratuais entre produtores integrados e integradores, e dá outras providências. Diário Oficial da União. Recuperado de:

http://www.planalto.gov.br/ccivil_03/_ato2015-2018/2016/lei/113288.htm.

Malhotra, N. K. (2012). Pesquisa de marketing: uma orientação aplicada (6a ed.). São Paulo, SP: Bookman.

Ménard, C. (2004). The economics of hybrid organizations. Journal of Institutional and Theoretical Economics, 160(3), 345-376. Recuperado de: www.jstor.org/stable/40752467.

Ménard, C. (2018). Research frontiers of new institutional economics. RAUSP Management Journal, 53(1), 3-10. Recuperado de: http://dx.doi.org/10.1016/j.rauspm.2017.12.002. 
Monteiro, G. F. A. (2017). On the relationship between antitrust and strategy: taking steps and thinking ahead. Revista de Administração (São Paulo), 52(3), 317-329. Recuperado de: http://dx.doi.org/10.1016/j.rausp.2017.05.004.

Monteiro, G. F. A., \& Zylbersztajn, D. (2011). Direitos de propriedade, custos de transação e concorrência: o modelo de Barzel. EconomicAnalysis of Law Review-EALR, 2(1), 95-114. Recuperado de: http://dx.doi.org/10.18836/2178-0587/ealr.v2n1p95-114.

Mozambani, C. I., Souza Filho, H. M., \& Miranda, B. V. (2019). Compromissos mútuos nas transações de hortícolas na Serra Fluminense. RAE - Revista de Administração de Empresas, 59(3), p. 195-208. Recuperado de: http://dx.doi.org/10.1590/S0034-759020190305.

Neves, L. W. A., Hamachera, S., \& Cavarda, L. F. (2014). Outsourcing from the perspectives of TCE and RBV: a multiple case study. Production, 24(3), 687-699. Recuperado de: https://doi.org/10.1590/S0103-65132013005000082.

Neves, M. F., Kalaki, R. B., Rodrigues, J. M., \& Gray, A. W. (2019). Strategic planning and management of food and agribusiness chains: the chainplan method (framework). RBGN-Review of Business Management, 21, 628-646.

Niesten, E., \& Jolink, A. (2015). The impact of alliance management capabilities on alliance attributes and performance: a literature review. International Journal of Management Reviews, 17(1), 69-100. Recuperado de: https://doi.org/10.1111/ijmr.12037.

Niesten, E., Jolink, A., Jabbour, A. B. L. S., Chappin, M. M. H., \& Lozano, R. (2017). Sustainable collaboration: the impact of governance and institutions on sustainable

performance. Journal of CleanerProduction, 155(2), 1-6. Recuperado de: https://dx.doi.org/10.1016/j.jclepro.2016.12.085.

Nogueira, C. R., Bánkuti, S. M. S., Lourenzani, A. E. B. S., Bánkuti, F. I., \& Lourenzani, W. L. (2018). Coordenação de sistemas agroalimentares diferenciados: um estudo sobre o leite orgânico no Paraná. Gestão \& Regionalidade, 34(100), 74-91. doi: https://doi.org/10.13037/gr.vol34n100.3696.

North, D. C. (1990). Institutions, institutional change and economic performance. Cambridge, UK: Cambridge University Press.

Paraná. Secretaria da Agricultura e do Abastecimento. (2015). Valor bruto da produção. Ano safra 2015. Disponível em: http://www.agricultura.pr.gov.br/vbp.

Peixe Br - Associação Brasileira Da Piscicultura. (2020). Anuário Peixe BR da piscicultura 2020. Recuperado de: https://www.peixebr.com.br/anuario2019/.

Peteraf, M. A. (1993). The cornerstone of competitive advantage: the resource-based view. Strategic Management Journal, 14(3), 179-191.

Pooe, R., \& Mahlangu, D. (2017). Enhancing SME performance through supply chain integration, collaborative planning, and supply chain capabilities. Journal of Contemporary Management, 14(1), 238-269.

Pooe, D., \& Munyanyi, W. (2019). The influence ofcollaboration-orientedorganisational capabilities onsupply chain competenceamong small and mediumenterprises. Acta Commercii, 19(2), a656. Recuperado de: https://doi.org/10.4102/ac.v19i2.656.

Reifschneider, F. J. B., \& Lopes, C. A. (2015).Horticultura brasileira sustentável: sonho eterno ou 
possibilidade futura? Revista de Política Agrícola, 24(2), 90-101. Recuperado de:

https://www.alice.cnptia.embrapa.br/alice/bitstream/doc/1025746/1/Horticulturabrasileira.pdf.

Saes, M. S. M. (2009). Uma visão integrativa das vertentes de estratégias. São Paulo, SP: Annablume.

Santos, N. M., Ferraz, I. N., Falqueto, J. M. Z., \& Verga, E. (2017). A teoria dos custos de transação nas pesquisas de estratégia no Brasil. Revista Ibero Americana de Estratégia, 16(2), 4-18. doi: 10.5585/riae.v16i2.2437

Santos, E. J., Lourenzani, W. L., \& Lourenzani, A. E. B. S. (2019). Coordenação do sistema agroindustrial do urucum na Microrregião de Dracena, Estado de São Paulo. Revista Brasileira de Gestão e Desenvolvimento Regional, 15(1), 110-123.

Storopoli, J. E., Binder, M. P., \& Maccari, E. A. (2013). Incubadora de empresas e o desenvolvimento de capacidades em empresas incubadas. Revista de Ciências da Administração, 15(35), 36-51. doi: http://dx.doi.org/10.5007/2175-8077.2013v15n35p36.

Trienekens, J. H. (2011). Agricultural value chains in developing countries: a framework for analysis. International Food and Agribusiness Management Review, 14(2), 51-82. doi: 10.22004 / ag.econ. 103987

Van Duren, E. M., Martin, L., \& Westgren, R. (1991). Assessing the competitiveness of Canada's agrifood industry. Canadian Journal of Agricultural Economics, 39(1991), 727-738. Recuperado de: https://doi.org/10.1111/j.1744-7976.1991.tb03630.x.

Zylbersztajn, D. (2005). Papel dos contratos na coordenação agro-industrial: um olhar além dos mercados. Revista de Economia e Sociologia Rural, 43(3), 385-420. doi: 10.1590/S010320032005000300001

Zylbersztajn, D., \& Neves, M. F. (2010). Economia \& gestão dos negócios agroalimentares. São Paulo, SP: Pioneira Thomson Learning.

Watanabe, K., Wever, M., Sousa, R. N. R. L., \& Koenig, C.C. (2016). Understanding the hierarchy governance choiceof some wineries in Brazil - case study of 3 Brazilian wineries. Revista de Administração (São Paulo), 51(1), 20-35. doi: 10.5700/rausp1221

Wilden, R., Devinney, T. M., \& Dowling, G. R. (2016). The architecture of dynamic capability research identifying the building blocks of a configurational approach. Academy of Management, 10(1), 9971076. Recuperado de: https://doi.org/10.1080/19416520.2016.1161966.

Williamson, O. E. (1991). Comparative economic organization: the analysis of discrete structural alternatives. Administrative Science Quarterly, 36(2), 269-296. doi: 10.2307 / 2393356

Williamson, O. E. (1985). The economic institutions of capitalism: firms, markets, relational contracting. New York, NY: Free Press.

Williamson, O. E. (1975). Markets and hierarchies: analysis and antitrust implications. New York, NY: Free Press.

Winkler, C. A. G., \& Souza, J. P. (2013). Condições de apropriação de renda no sistema agroindustrial do café. Caderno de Administração, 20(2), 23-37. doi: https://doi.org/10.4025/cadadm.v20i2.20846. 